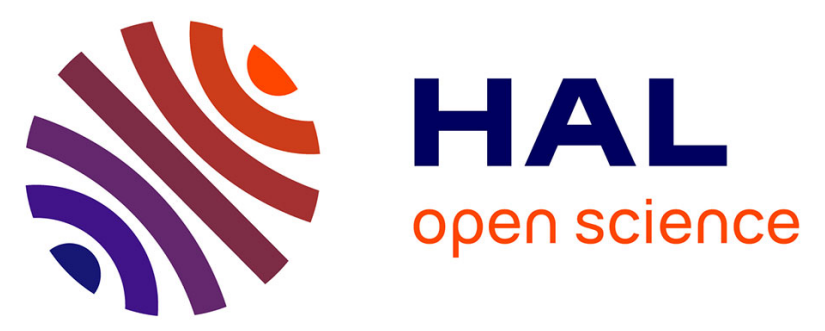

\title{
Bio-Based Polyricinoleate and Polyhydroxystearate: Properties and Evaluation as Viscosity Modifiers for Lubricants
}

Hélène Méheust, Jean-François Le Meins, Etienne Grau, Henri Cramail

\section{To cite this version:}

Hélène Méheust, Jean-François Le Meins, Etienne Grau, Henri Cramail. Bio-Based Polyricinoleate and Polyhydroxystearate: Properties and Evaluation as Viscosity Modifiers for Lubricants. ACS Applied Polymer Materials, 2021, 3 (2), pp.811-818. 10.1021/acsapm.0c01153 . hal-03109425

\section{HAL Id: hal-03109425 \\ https://hal.science/hal-03109425}

Submitted on 13 Jan 2021

HAL is a multi-disciplinary open access archive for the deposit and dissemination of scientific research documents, whether they are published or not. The documents may come from teaching and research institutions in France or abroad, or from public or private research centers.
L'archive ouverte pluridisciplinaire HAL, est destinée au dépôt et à la diffusion de documents scientifiques de niveau recherche, publiés ou non, émanant des établissements d'enseignement et de recherche français ou étrangers, des laboratoires publics ou privés.

\section{(1) (1) $\$$}

Distributed under a Creative Commons Attribution - NonCommercial - NoDerivatives| 4.0 


\title{
Bio-based polyricinoleate and polyhydroxystearate:
}

\section{properties and evaluation as viscosity modifiers for}

\section{lubricants}

\author{
Hélène Méheust,${ }^{\dagger}$ Jean-François Le Meins,${ }^{\dagger}$ Etienne Grau,${ }^{\dagger *}$ Henri Cramail ${ }^{\dagger *}$
}

${ }^{\dagger}$ Univ. Bordeaux, CNRS, Bordeaux INP, LCPO, UMR 5629, F-33600, 16, Avenue Pey Berland, 33607, Pessac, France.

*Etienne.grau@enscbp.fr ; henri.cramail@enscbp.fr

\begin{abstract}
This paper aims to design bio-based polyester as viscosity modifiers for lubricant properties. Bio-based polyricinoleate (PRic) and its saturated homologous polyhydroxystearate (PHS) have been synthesized from fatty acid methyl esters. The polycondensation performed in bulk in onestep reaction without any purification leads to two series of polyesters within a large range of molecular weights, with $\mathrm{M}_{\mathrm{w}}$ between 3 and $130 \mathrm{~kg} \cdot \mathrm{mol}^{-1}$. Their thermal properties were investigated. Good thermal stability was observed with degradation temperatures above $300{ }^{\circ} \mathrm{C}$. As expected, PRic appeared to be amorphous with a particularly low glass transition temperature while PHS is semi-crystalline. A rheological study determined that polyricinoleate entangled when its molecular weight is above $25 \mathrm{~kg} \cdot \mathrm{mol}^{-1}$. These two bio-based and biodegradable polymers were then evaluated as viscosity modifiers in both organic and mineral oils. PHS with high molecular
\end{abstract}


weights appeared to be an excellent thickener as well as a good Viscosity Index improver with a VI increase above +50 in organic lubricant oil and +64 in mineral oil.

Keywords: polyricinoleate, polyhydroxystearate, lubricant, viscosity modifiers, thickeners, Viscosity Index

\section{Introduction}

The global concern over environmental pollution has led to a growing interest in the use of renewable resources in the fields of polymers and lubricants. The abundant availability and relatively low cost of vegetable oils make them one of the most essential sustainable resources for the chemical industries. ${ }^{1-3}$ Castor oil, in particular, represents a high interest for industrial applications; especially, ricinoleic acid can be recovered from castor oil triglycerides to its acidic form by saponification or to methyl ricinoleate by methanolysis. ${ }^{4,6}$ The natural presence of one $\mathrm{OH}$ group and a carboxylic or ester terminal function of this mono-unsaturated fatty acid/ester $(\mathrm{C} 18: 1, \mathrm{OH})$ enables its self-condensation to produce polyricinoleate which generally exhibit low molecular weights, i.e. 3-11 kg.mol ${ }^{-1}{ }^{5-12}$ Only Matsumura and coll. ${ }^{13,14}$ synthesized amorphous polyricinoleate with $\mathrm{M}_{\mathrm{w}}$ up to $100 \mathrm{~kg} \cdot \mathrm{mol}^{-1}$ by mean of enzymatic catalysis. However, these systems require a large quantity of enzyme, 50 wt.\% with respect to the monomer, very long reaction times and the use of solvents. More recently, our group reported the polymerization of methyl ricinoleate and its copolymerization with 12-hydroxystearate using $\operatorname{Ti}(\mathrm{O} i \mathrm{Pr})_{4}$ as a catalyst leading to the formation of polyricinoleate with $\mathrm{M}_{\mathrm{w}}$ up to $60 \mathrm{~kg} \cdot \mathrm{mol}^{-1} \cdot{ }^{15}$

This amorphous bio-based polyester appeared to be soluble in non-polar solvent and oils with thickening ability. ${ }^{10}$ Its high miscibility with apolar systems, its biodegradability feature and stability against temperature make polyricinoleate a promising environmental-friendly viscosity modifier for lubricants. ${ }^{7,10,13,16}$ 
The role of a viscosity modifier is to thicken a lubricant oil and to reduce its viscosity loss at high temperature which is usually determined by the Viscosity Index (VI). Thanks to the addition of a viscosity modifier, a lubricant can be used over a large range of temperatures. ${ }^{17,18}$ Currently, mostly petroleum-based polymers such as polyalkylmethacrylates and polyolefins are used as viscosity modifiers. ${ }^{19-21}$ While the research is active on bio-compatible lubricants ${ }^{22-24}$, only a few solutions have been described to replace viscosity modifier additives with bio-based polymers in accordance to new environmental concerns. ${ }^{25,26}$

Herein, polyricinoleate (PRic) was developed as well as its saturated homologous poly(12hydroxystrearate) (PHS) within a large range of molecular weights in order to evaluate these biobased polyesters as potential viscosity modifiers. The molecular weights were controlled as a function of the reaction time. Both polyesters were synthesized using one-step bulk polycondensation, without further purification, and their thermal and rheological properties, in the bulk state, analyzed as a function of their molecular weight. Finally, the potential of PRic and PHS as viscosity modifiers in mineral and organic lubricant oils were evaluated.

\section{Material and methods}

\section{Materials}

Bio-based methyl ricinoleate (Nu-chek-prep, $>99 \%$ ) and methyl hydroxystearate (Nu-checkprep, $>99 \%$ ) were used without further purification for polyester synthesis. Titanium isopropoxyde (Ti(OiPr) $4,99.99 \%$, Acros Organics) was used as catalyst as received. Dichloromethane (DCM) was supplied from $\mathrm{ABCR}$ and used as received. Deuterated solvents were purchased from Eurisotop and used as received. Commercial mineral paraffinic oil, the Yubase 4+ (MO) and organic triglyceride oil, Radialube 7386 (OTO) were kindly supplied by TOTAL and Oleon, respectively. Their properties are given in Table 1. Two commercial viscosity modifiers were 
Author manuscript of article published in ACS Applied Polymer Materials 2021, https://doi.org/10.1021/acsapm.0c01153

kindly provided from Croda (Ref-O, specifically used in organic oil OTO) and from Chevron (RefM, specifically used in mineral oil). 
Table 1: Oil characteristics, determined experimentally or from producer data sheet [in brackets]

\begin{tabular}{|c|c|c|}
\hline Lubricant oils & MO & OTO \\
\hline Density $^{1}$ & $0.8226[0.825]$ & $0.941[0.945]$ \\
\hline $\operatorname{Mn}\left(\text { g.mol }^{-1}\right)^{2}$ & 600 & $750[512.8]$ \\
\hline $\boldsymbol{\boxplus}^{2}$ & 1 & 1 \\
\hline Flash point $\left({ }^{\circ} \mathrm{C}\right)$ & {$[220]$} & {$[235]$} \\
\hline$\eta$ at $40^{\circ} \mathrm{C}\left(\mathrm{mm}^{2} \cdot \mathrm{s}^{-1}\right)^{1}$ & 18.6 & 20.4 \\
\hline$\eta$ at $100^{\circ} \mathrm{C}\left(\mathrm{mm}^{2} . \mathrm{s}^{-1}\right)^{1}$ & $4.3[4.1]$ & $4.6[4.5]$ \\
\hline Viscosity Index VI & 128 & 152 \\
\hline \multicolumn{3}{|c|}{$\begin{array}{l}1-\eta=\text { dynamic viscosity, } 1 \mathrm{~mm}^{2} \cdot \mathrm{s}^{-1}=1 \mathrm{cSt} \text {; Obtained using a densimeter-viscosimeter at } \\
40^{\circ} \mathrm{C} \text {. }\end{array}$} \\
\hline \multicolumn{3}{|c|}{ 2-Obtained by SEC in THF, PS calibration, $\oslash=\mathrm{M}_{\mathrm{w}} / \mathrm{M}_{\mathrm{n}}$, the dispersity. } \\
\hline
\end{tabular}

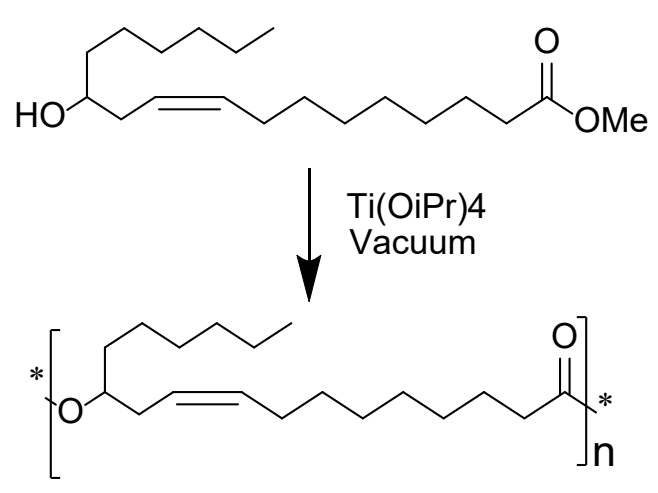

Polyricinoleate

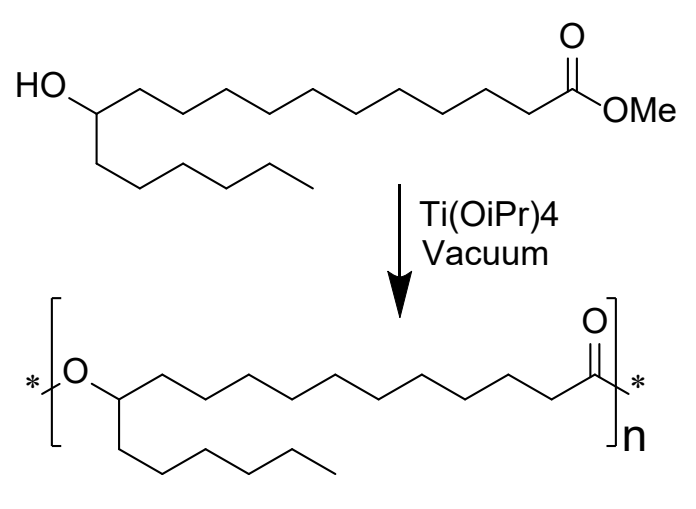

Poly(12-hydroxystearate)

Figure 1: Synthesis of PRic and PHS

General procedure of polycondensation 
PRic and PHS were prepared from methyl ester ricinoleate (1.5 g, $4.8 \mathrm{mmol})$ and methyl-12hydroxystearate $(1.5 \mathrm{~g}, 4.8 \mathrm{mmol})$, respectively (see Figure 1), dried overnight under vacuum at $70{ }^{\circ} \mathrm{C}$ under mechanical stirring in $50 \mathrm{~mL}$ Schlenk flask at $200 \mathrm{rpm}$. The mixture was cooled at room temperature under static vacuum and a 5 wt. $\%$ solution of $\mathrm{Ti}(\mathrm{O} i \mathrm{Pr})_{4}$ in $\mathrm{DCM}(0.015 \mathrm{~g}$ of catalyst, $0.053 \mathrm{mmol}, 1 \mathrm{wt} . \%$ ) was added under nitrogen flow. The mixture was stirred at room temperature for $30 \mathrm{~min}$ under static nitrogen then put under vacuum and heated at $70{ }^{\circ} \mathrm{C}$ for 30 min. Then the mixture was heated at $120{ }^{\circ} \mathrm{C}$ for one hour, $140{ }^{\circ} \mathrm{C}$ for another hour and $180{ }^{\circ} \mathrm{C}$ for 45 hours still under dynamic vacuum to remove the methanol $(\mathrm{MeOH})$ sub-product and mechanical stirring at $200 \mathrm{rpm}$. After 48 hours reaction, stirring was stopped, the highly viscous mixture was cooled to room temperature and the flask was opened to air in order to stop the reaction. No purification was performed on the final product.

Methyl ricinoleate: $\delta(\mathrm{ppm}): 0.82(\mathrm{C} 18,-\mathrm{CH} 3,3 \mathrm{H}, \mathrm{t}) ; 1.24(\mathrm{C} 4-\mathrm{C} 7, \mathrm{C} 14-\mathrm{C} 17, \mathrm{CH} 2,16 \mathrm{H}, \mathrm{m})$; $1.39(\mathrm{C} 13, \mathrm{CH} 2,2 \mathrm{H}, \mathrm{m}) ; 1.55(\mathrm{C} 3, \mathrm{CH} 2,2 \mathrm{H}, \mathrm{m}) ; 1.90(\mathrm{OH}, 1 \mathrm{H}, \mathrm{s}) ; 1.98(\mathrm{C} 8, \mathrm{CH} 2,2 \mathrm{H}, \mathrm{m}) ; 2.15$ $(\mathrm{C} 11, \mathrm{CH} 2,2 \mathrm{H}, \mathrm{t}) ; 2.23(\mathrm{C} 2, \mathrm{CH} 2,2 \mathrm{H}, \mathrm{m}) ; 3.5(\mathrm{C} 12, \mathrm{CH}, 1 \mathrm{H}, \mathrm{m}) ; 3.6(\mathrm{OCH} 3,3 \mathrm{H}, \mathrm{s}) ; 5.36$ and $5.46(\mathrm{C} 10$ and $\mathrm{C} 9,-\mathrm{CH}=\mathrm{CH}-, 1 \mathrm{H}$ and $1 \mathrm{H}, \mathrm{m})$

Polyricinolate: $\delta(\mathrm{ppm}): 0.82$ (C18, -CH3, 3H, t); 1.24 (C4-C7, C14-C17, CH2, 16H, m); 1.45 $(\mathrm{C} 13, \mathrm{CH} 2,2 \mathrm{H}, \mathrm{m}) ; 1.55(\mathrm{C} 3, \mathrm{CH} 2,2 \mathrm{H}, \mathrm{m}) ; 1.94(\mathrm{C} 8, \mathrm{CH} 2,2 \mathrm{H}, \mathrm{m}) ; 2.2(\mathrm{C} 2$ and $\mathrm{C} 11, \mathrm{CH} 2, \mathrm{CH} 2$, $4 \mathrm{H}, \mathrm{m}) ; 3.6(\mathrm{OCH} 3,3 \mathrm{H}, \mathrm{s}) ; 4.81(\mathrm{C} 12, \mathrm{CH}, 1 \mathrm{H}, \mathrm{m}) ; 5.27$ and $5.38(\mathrm{C} 10$ and $\mathrm{C} 9,-\mathrm{CH}=\mathrm{CH}-, 1 \mathrm{H}$ and $1 \mathrm{H}, \mathrm{m})$

Methyl-12-hydroxystearate: $\delta$ (ppm): 0.84 (C18, -CH3, 3H, t); 1.23 (C4-C10, C14-C17, CH2, 22H, m); 1.39 (C11 and C13, CH2, CH2, 4H, m); $1.58(\mathrm{C} 3, \mathrm{CH} 2,2 \mathrm{H}, \mathrm{m}) ; 2.26(\mathrm{C} 2, \mathrm{CH} 2,2 \mathrm{H}, \mathrm{m})$; $3.54(\mathrm{C} 12, \mathrm{CH}, 1 \mathrm{H}, \mathrm{m}) ; 3.62(\mathrm{OCH} 3,3 \mathrm{H}, \mathrm{s})$ 
Polyhydroxystearate: $\delta$ (ppm): 0.84 (C18, -CH3, 3H, t); $1.23(\mathrm{C} 4-\mathrm{C} 10, \mathrm{C} 14-\mathrm{C} 17, \mathrm{CH} 2,22 \mathrm{H}, \mathrm{m})$;

1.39 (C11 and $\mathrm{C} 13, \mathrm{CH} 2, \mathrm{CH} 2,4 \mathrm{H}, \mathrm{m}) ; 1.58(\mathrm{C} 3, \mathrm{CH} 2,2 \mathrm{H}, \mathrm{m}) ; 2.26(\mathrm{C} 2, \mathrm{CH} 2,2 \mathrm{H}, \mathrm{m}) ; 4.86$

$(\mathrm{C} 12, \mathrm{CH}, 1 \mathrm{H}, \mathrm{m})$

\section{Characterization}

\section{Nuclear Magnetic Resonance (NMR)}

All the ${ }^{1} \mathrm{H}$ and $1 \mathrm{D}{ }^{13} \mathrm{C}-\mathrm{NMR}$ (DEPT) spectra were recorded on Bruker Avance 400 spectrometer (400 MHz and $100.63 \mathrm{MHz}$ for ${ }^{1} \mathrm{H}$ and ${ }^{13} \mathrm{C}$, respectively) by using $\mathrm{CDCl}_{3}$ as a solvent at room temperature. ${ }^{1} \mathrm{H}$ NMR analyses were performed with 16 scans. Multiplicity dependent $1 \mathrm{D}{ }^{13} \mathrm{C}$ NMR experiment (DEPT) was performed with deptsp135 pulse program (256 scans) Twodimensional analysis such as ${ }^{1} \mathrm{H}-{ }^{1} \mathrm{H}$ COSY (COrrelation SpectroscopY) was also performed on the same spectrometer.

\section{Size Exclusion Chromatography in THF (SEC)}

Polymer molecular weights were determined by Size Exclusion Chromatography (SEC) using tetrahydrofuran (THF) as the eluent. Measurements in THF were performed on an Ultimate 3000 system from Thermoscientific equipped with diode array detector DAD. The system also includes a multi-angle light scattering detector MALS and differential refractive index detector dRI from Wyatt technology. Polymers were separated on three G2000, G3000 and G4000 TOSOH HXL gel columns (300 x $7.8 \mathrm{~mm})$ (exclusion limits from $1000 \mathrm{Da}$ to $400000 \mathrm{Da})$ at a flowrate of $1 \mathrm{~mL}^{\mathrm{min}}{ }^{-}$

${ }^{1}$. Columns temperature was held at $40^{\circ} \mathrm{C}$. Polystyrene was used as the standard.

Differential Scanning Calorimetry (DSC)

Differential Scanning Calorimetry (DSC) measurements were performed on DSC Q100 (TA Instruments). The sample was heated from $-130{ }^{\circ} \mathrm{C}$ to $150^{\circ} \mathrm{C}$ at a rate of $10^{\circ} \mathrm{C} \cdot \mathrm{min}^{-1}$. Consecutive 
cooling and second heating run were also performed at $10{ }^{\circ} \mathrm{C} \cdot \mathrm{min}^{-1}$. The glass transition temperatures $\left(\mathrm{T}_{\mathrm{g}}\right)$ and melting temperatures $\left(\mathrm{T}_{\text {melt }}\right)$ were calculated from the second heating run. Crystallization temperatures $\left(\mathrm{T}_{\text {Crys }}\right)$ were calculated from the cooling run.

\section{$\underline{\text { Thermogravimetric analysis (TGA) }}$}

Thermogravimetric analyses were performed on TGA-Q500 system from TA instruments at a heating rate of $10{ }^{\circ} \mathrm{C} \cdot \mathrm{min}^{-1}$ under nitrogen atmosphere from room temperature to $600^{\circ} \mathrm{C}$.

\section{$\underline{\text { Rheological measurements }}$}

The complete methodology is described in supporting information. Rheological measurements were monitored using an Anton Paar Physica MCR302 operating in the parallel plates geometry (diameter $8 \mathrm{~mm}$ ). The measurements were performed under nitrogen flow in the environmental chamber to avoid potential moisture effects. The temperature was controlled by Peltier device and the gap between plates was fixed at $1 \mathrm{~mm}$. Samples were loaded at room temperature. The sample was stabilized at the desired temperature for $5 \mathrm{~min}$ before the measurement started.

\section{$\underline{\text { Preparation of oil blended with viscosity modifiers (additives) }}$}

Viscosity modifiers were dissolved in the mineral or organic base oils at the concentration of 3 wt.\%. The mixture was heated at $100{ }^{\circ} \mathrm{C}$ overnight under magnetic stirring to promote the solubilization and then cooled down without stirring at room temperature for 24 hours. The solubility of the additive in the oil was evaluated macroscopically. Samples were degassed under vacuum and magnetic stirring for 30 minutes right before viscosity measurement using a by LOVIS 2000 densimeter-viscometer.

\section{$\underline{\text { Viscosity measurements }}$}

The viscosimetric tests were performed on a LOVIS 2000 apparatus from Anton Paar at several temperatures: $20^{\circ} \mathrm{C}, 40{ }^{\circ} \mathrm{C}, 60^{\circ} \mathrm{C}, 80^{\circ} \mathrm{C}$ and $100^{\circ} \mathrm{C}$. Around $3 \mathrm{~mL}$ of solution were added in the 
densimeter cell and the capillary tube $(\varnothing 1.8 \mathrm{~mm}$ for oils and $\varnothing 1.59 \mathrm{~mm}$ for dodecane $)$ containing a steel ball $\left(\varnothing 1.5 \mathrm{~mm}, \mathrm{~d}=7.68 \mathrm{~g} . \mathrm{cm}^{-3}\right)$. The density, $d$, apparent viscosity, $\eta$ (mPa.s) and the kinematic viscosity, $v\left(\mathrm{~mm}^{2} \cdot \mathrm{s}^{-1}\right)$, with $v=\eta / d$, are determined directly from the apparatus. The relative viscosity, $\eta_{r}$, was then calculated following equation 1 .

$$
\eta_{r}=\frac{\eta}{\eta_{0}} \text { Eq. } 1
$$

The relative viscosity, i.e. the viscosity of a system "additive in oil" ( $\eta$ ) divided by the viscosity of the oil alone $(\eta 0)$, is used to evaluate the contribution of an additive to the viscosity of a solution. It allows to estimate the thickening efficiency of this additive.

The kinematic viscosities at $40{ }^{\circ} \mathrm{C}, v_{40^{\circ} \mathrm{C}}$, and $100{ }^{\circ} \mathrm{C}, v_{100^{\circ} \mathrm{C}}$, were used to calculate the Viscosity Index (VI) according to Eq. 2 ASTM D 2270-10. ${ }^{29}$

$$
\mathrm{VI}=\frac{v_{100^{\circ} \mathrm{C}}}{v_{40^{\circ} \mathrm{C}}} \mathrm{Eq} .2
$$

The $\mathrm{Q}$ factor, defined according to equation 3, were calculated from specific viscosities $\eta_{s p}$, at $40^{\circ} \mathrm{C}$ and $100^{\circ} \mathrm{C}$, obtained according to equation 4 .

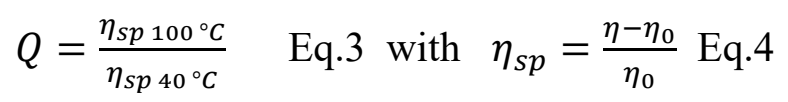

The $\mathrm{Q}$ value is the ratio between the specific viscosities at $40^{\circ} \mathrm{C}\left(\eta_{s p} 40^{\circ} \mathrm{C}\right)$ and at $100^{\circ} \mathrm{C}$ $\left(\eta_{s p 100{ }^{\circ} \mathrm{C}}\right)$. Specifically, $0<\mathrm{Q}<1$ indicates that the thickening power of the additive is less significant at $100^{\circ} \mathrm{C}$ than at $40^{\circ} \mathrm{C}$. Conversely, Q values $>1$ indicate the thickening power is more prominent at high temperature. The highest the $\mathrm{Q}$ value, the highest the additive capability to reduce the oil viscosity loss at high temperature. 


\section{Results and discussion}

Syntheses of polyricinoleate and polyhydroxystearate within a broad range of molecular weights

Polyricinoleate and polyhydroxystearate were synthesized by polycondensation of methyl ricinoleate and methyl-12-hydroxystearate, respectively. Different molecular weights were targeted. Consequently, the choice of precursors, as well as the reaction conditions, were investigated to obtain high molecular weight polyester. Both A-B monomers were selected with a grade of purity above $99 \%$ in order to limit secondary reaction and polymerization termination due to the presence of impurities.

According to the literature, in the case of transesterification with hydroxyl-ester interchange reaction, $\mathrm{Ti}(\mathrm{O} i \mathrm{Pr})_{4}$ is largely described as a very efficient catalyst leading to high molecular weight polyesters $^{30-32}$ and notably for the synthesis of poly(ethylene naphtalate) $)^{33}$, poly(ethylene terephthalate) $)^{30,34}$ and, more recently, linear bio-based polyesters ${ }^{32,35,36}$ Consequently, this organometallic catalyst was selected. A temperature of $180^{\circ} \mathrm{C}$ was chosen as a good compromise between high catalytic activity and the limitation of transfer reactions and terminations (especially due to the carbon-carbon double bond in the case of methyl ricinoleate). Finally, polymerization was performed in bulk, thus avoiding further treatment to remove the solvent. However, the high viscosity of the polymerization medium tends to slow down the polymerization process and limit the reaction extent. In order to overcome this issue, a mechanical stirring was used during polymerization process when high molecular weights PRic or PHS were targeted. Polyesters were then analyzed without further purification.

The structures of the polyesters were confirmed by ${ }^{1} \mathrm{H}$ NMR in agreement with previous publication $^{15}$ (see Figure 2 for PRic and Figure SI-1-3 in Supporting Information for PHS). 
(1)

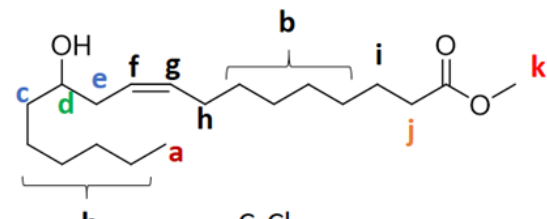

b

(2)
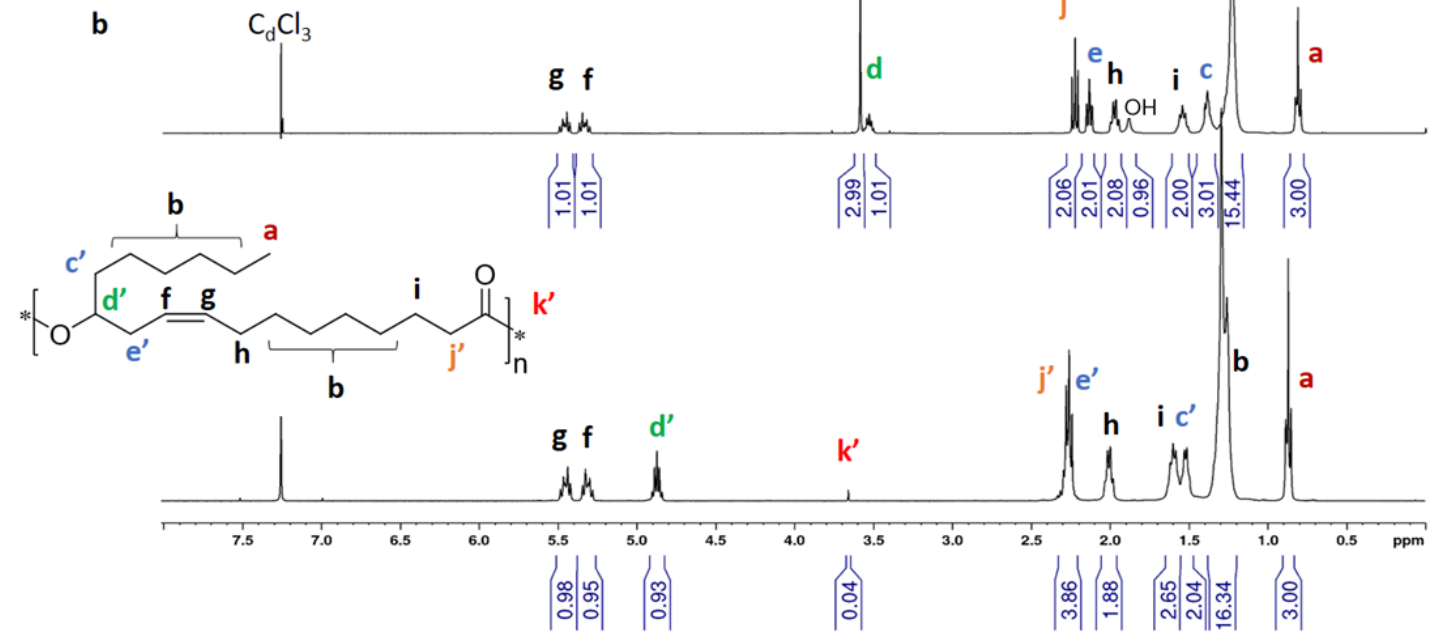

Figure2: ${ }^{1} \mathrm{H}$ NMR spectra of (1) methyl ricinoleate monomer and (2) polyricinoleate in $\mathrm{CDCl}_{3}$

In both cases, the peak at $0.82 \mathrm{ppm}$, representative of the terminal $\mathrm{CH}_{3}$ protons of the fatty methyl esters, is used as a reference. The polycondensation is confirmed by the drastic decrease of the characteristic methoxy peak at $3.59 \mathrm{ppm}$ and the shift of the peak corresponding to the proton in $\alpha$ position of the $\mathrm{OH}$ group from 3.5 to $4.88 \mathrm{ppm}$. The protons in $\alpha$ and $\beta$ positions of the ester group are assigned at $2.26 \mathrm{ppm}$ and $1.6 \mathrm{ppm}$, respectively. In the case of polyricinoleate, there is also a small shift of the protons in $\beta$ position of the $\mathrm{OH}$ group, from $1.40 \mathrm{ppm}$ to $1.55 \mathrm{ppm}$ and $2.15 \mathrm{ppm}$ to $2.26 \mathrm{ppm}$. 
Table 2: Reaction extent (p), degree of polymerization (DPn), molecular weights and solubility in mineral oil (MO) or organic triglyceride oil (OTO) of a series of PRic and PHS

\begin{tabular}{|c|c|c|c|c|c|c|c|c|c|}
\hline Entry & $\begin{array}{l}\text { Time } \\
\text { (h) }\end{array}$ & $p^{1}$ & DPn $^{1}$ & $\begin{array}{c}\mathbf{M}_{\mathbf{n}}{ }^{1} \\
\left(\mathrm{~g} \cdot \mathrm{mol}^{-1}\right)\end{array}$ & $\begin{array}{c}\mathrm{Mn}_{\mathbf{n}}{ }^{2} \\
\left(\mathrm{~g} \cdot \mathrm{mol}^{-1}\right)\end{array}$ & $\begin{array}{c}\mathbf{M}_{\mathrm{w}}{ }^{2} \\
\left(\mathrm{~g} \cdot \mathrm{mol}^{-1}\right)\end{array}$ & $\boldsymbol{D}^{2}$ & $\begin{array}{c}\text { Sol. } \\
\text { in } \mathrm{MO}^{3}\end{array}$ & $\begin{array}{c}\text { Sol. } \\
\text { in OTO }\end{array}$ \\
\hline PRic-1 $^{\text {a }}$ & 6 & 0.894 & 9.4 & 3000 & 4000 & 6100 & 1.5 & Yes & Yes \\
\hline PRic-2 a & 8 & 0.902 & 10.2 & 4200 & 7200 & 10600 & 1.5 & Yes & Yes \\
\hline PRic-3 $^{\text {a }}$ & 24 & 0.977 & 45 & 12400 & 18200 & 32200 & 1.7 & Yes & No \\
\hline PRic-4 a & 48 & 0.984 & 63 & 19800 & 21700 & 47100 & 2.2 & No & No \\
\hline PRic-5 b & 48 & 0.991 & 110 & 34000 & 28100 & 131500 & 4.6 & No & No \\
\hline PHS-1 ${ }^{a}$ & 8 & 0.960 & 25 & 7700 & 8100 & 17500 & 2.1 & Yes & Yes \\
\hline PHS-2 ${ }^{a}$ & 48 & 0.990 & 100 & 30200 & 24000 & 68100 & 2.4 & Yes & Yes \\
\hline PHS-3 ${ }^{\text {b }}$ & 48 & 0.996 & 225 & 60000 & 28500 & 78400 & 2.5 & Yes & Yes \\
\hline
\end{tabular}

Reaction conditions: $180^{\circ} \mathrm{C}, 1 \mathrm{wt} . \%$ of $\mathrm{Ti}(\mathrm{OiPr})_{4}$ in the melt under vacuum, $200 \mathrm{rpm}$

a: Magnetic stirring and b: mechanical stirring

1 Obtained by ${ }^{1} \mathrm{H}$ NMR using $\mathrm{OCH}_{3}$ peak at $3.6 \mathrm{ppm}$ for calculation

$2 \boldsymbol{\oplus}=\mathrm{M}_{\mathrm{w}} / \mathrm{Mn}$, dispersity. Obtained by SEC in THF - triple detection, dn/dc values used for calculation

3 Polymer solubility at $3 \mathrm{wt} \%$ in oil after one night heated at $100^{\circ} \mathrm{C}$ under stirring and 24 hours at $20^{\circ} \mathrm{C}$

As indicated in Table 2, molecular weights of PRic and PHS were impacted by the polymerization duration and mode of stirring. SEC traces (Figure SI-4, see Supporting Information) shows the standard step-growth polymerization profiles with a molecular weight distribution shifting to the higher molecular weights with time. $\mathrm{M}_{\mathrm{n}}$ values obtained by SEC analysis using triple detection are in agreement with the ones determined by ${ }^{1} \mathrm{H}$ NMR using chainend analysis. PHS-3 is the only exception where $M_{n}$ predicted by Carothers equation is twice the 
one obtained by SEC. This may be due to secondary reactions, such as cyclization, that decrease the concentration of terminal methyl esters. In the case of PRic, a broad range of molecular weights was obtained from $\mathrm{M}_{\mathrm{w}}=6 \mathrm{~kg} \cdot \mathrm{mol}^{-1}$ to $\mathrm{M}_{\mathrm{w}}=131 \mathrm{~kg} \cdot \mathrm{mol}^{-1}\left(17\right.$ and $78 \mathrm{~kg} \cdot \mathrm{mol}^{-1}$ for PHS) which is the highest molecular weight reported in literature to the best of our knowledge. ${ }^{13-15}$ While all polyesters exhibit a dispersity close to 2 as it is expected, the dispersity around 4.6 for PRic-5 suggests the occurrence of side reactions. Indeed, while a small fraction of oligomers can be detected whatever the final molecular weight distribution, in the case of PRic-5, this fraction is more intense leading to higher dispersity. This peak may be due to a backbiting reaction leading to the formation of ricinoleate lactone. Since there is no apparent broadening of the polymer peak (see Figure SI-4) the presence of this oligomeric fraction explains the dispersity value obtained.

\section{Thermal properties}

The thermal stabilities of the PRic and PHS were investigated by thermogravimetric analyses (TGA), under a nitrogen stream at a heating rate of $10{ }^{\circ} \mathrm{C} \cdot \mathrm{min}^{-1}$. The polymer degradation temperatures at $5 \mathrm{wt} . \%$ are reported in Table 3. Compared to both monomers which begin to degrade at $160{ }^{\circ} \mathrm{C}$, the thermal stability of the polymer is higher with a degradation above $300{ }^{\circ} \mathrm{C}$ for all the polyesters. PHS possesses slightly better thermal stability compared to PRic which can be explained by the presence of unsaturation in the backbone. No influence of the polyester molecular weights on the temperature of degradation can be noticed.

PRic and PHS were also analyzed by differential scanning calorimetry analysis, traces of which are displayed in Figure 3. The glass transition temperature, $\mathrm{T}_{g}$, the crystallization temperature, $\mathrm{T}_{\text {cris }}$, the melting temperature, $\mathrm{T}_{\text {melt }}$ and corresponding enthalpies were recorded after the second heating scan at a rate of $10^{\circ} \mathrm{C} \cdot \mathrm{min}^{-1}$. All the results are reported in Table 3 . 
Table 3: Thermal behavior of PRic and PHS determined by TGA and DSC

\begin{tabular}{|c|c|c|c|c|c|c|c|c|c|}
\hline Entry & $\begin{array}{c}M_{n}{ }^{1} \\
\left(\mathrm{~g} \cdot \mathrm{mol}^{-1}\right)\end{array}$ & $\begin{array}{c}\mathbf{M}_{w}{ }^{1} \\
(\text { g.mol } \\
\end{array}$ & $\oplus^{1}$ & $\begin{array}{c}\mathbf{T d}_{5 \%}{ }^{2} \\
\left({ }^{\circ} \mathrm{C}\right)\end{array}$ & $\begin{array}{c}\mathrm{T}_{g}{ }^{2} \\
\left({ }^{\circ} \mathbf{C}\right)\end{array}$ & $\begin{array}{l}\mathbf{T}_{\text {melt }}{ }^{3} \\
\left({ }^{\circ} \mathbf{C}\right)\end{array}$ & $\begin{array}{l}\Delta \mathbf{H}_{\mathrm{m}^{3}} \\
(\mathrm{~J} / \mathrm{g})\end{array}$ & $\begin{array}{l}\mathrm{T}_{\text {cris }}{ }^{3} \\
\left({ }^{\circ} \mathrm{C}\right)\end{array}$ & $\begin{array}{l}\Delta \mathbf{H}_{\mathrm{c}}{ }^{3} \\
(\mathrm{~J} / \mathrm{g})\end{array}$ \\
\hline MRic & - & - & - & 160 & - & -7 & 79 & -41 & 28 \\
\hline PRic-1 & 4000 & 6100 & 1.5 & 296 & -77 & - & - & - & - \\
\hline PRic-2 & 7200 & 10600 & 1.5 & & -71 & - & - & - & - \\
\hline PRic-3 & 18200 & 32200 & 1.7 & 303 & -69 & - & - & - & - \\
\hline PRic-4 & 21700 & 47100 & 2.2 & & -68 & - & - & - & - \\
\hline PRic-5 & 28100 & 131500 & 4.6 & 300 & -68 & - & - & - & - \\
\hline MHS & - & - & - & 160 & - & 54 & 235 & 47 & 201 \\
\hline PHS-1 & 8100 & 17500 & 2.1 & 307 & -37 & -20 & 30 & -31 & 30 \\
\hline PHS-2 & 24000 & 68100 & 2.4 & 309 & -44 & -22 & 22 & -33 & 29 \\
\hline PHS-3 & 28500 & 78400 & 2.5 & 314 & -41 & -22 & 27 & -34 & 25 \\
\hline
\end{tabular}

1 Obtained by SEC in THF - triple detection, dn/dc values using for calculation

2 Temperature for $5 \mathrm{wt} \%$ degradation- Obtained by TGA

3 Obtained by DSC- Second heating cycle at a rate of $10^{\circ} \mathrm{C} \mathrm{min}^{-1}$
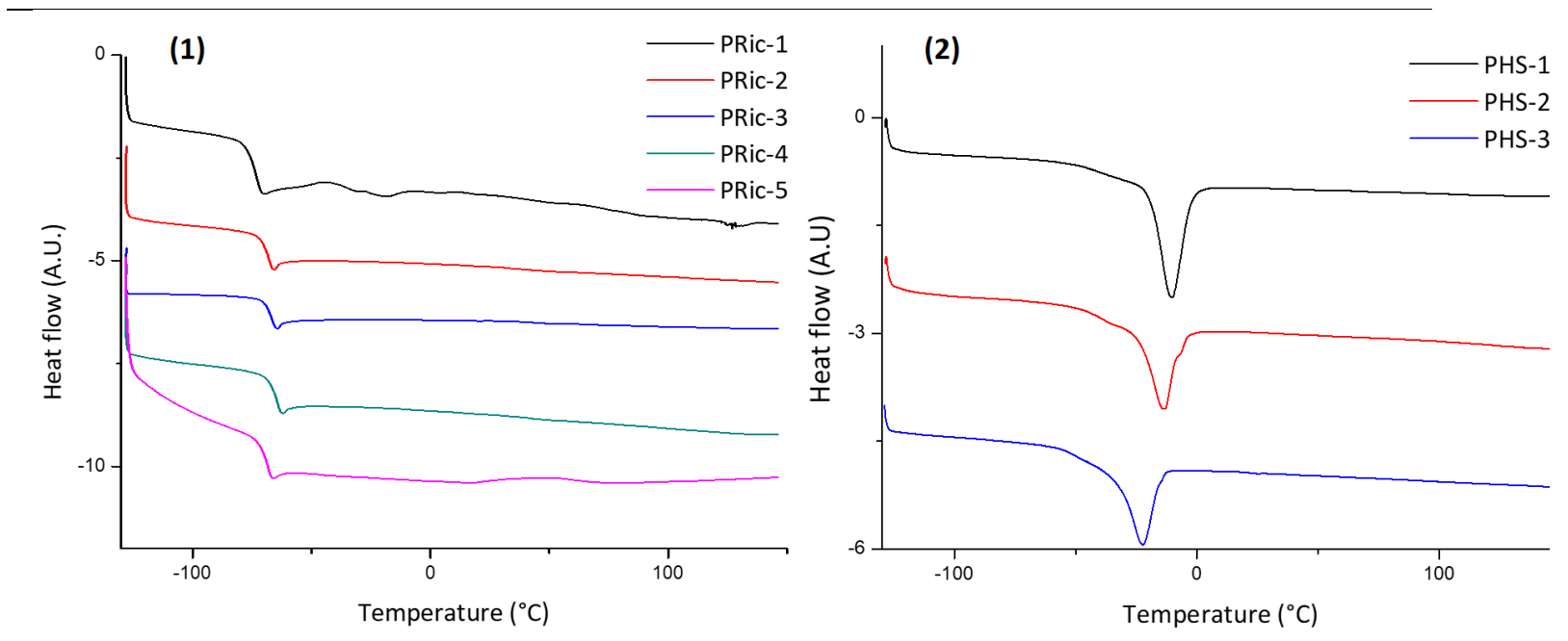

Figure 3: DSC traces of (1) PRic and (2) PHS with both several molar masses. Second heating cycle rate of $10{ }^{\circ} \mathrm{C} \cdot \mathrm{min}^{-1}$ 
While the two polymer structures are identical except the presence of a double bond in cis configuration along the polymer backbone, the thermal behavior of PRic and PHS are dramatically different. On the first hand, polyhydroxystearate shows a semi-crystalline behavior with a melting temperature of about $-20{ }^{\circ} \mathrm{C}$ with a $\mathrm{T}_{g}$ around $-40{ }^{\circ} \mathrm{C}$. On the other hand, PRic behaves as a completely amorphous polymer with a low $\mathrm{Tg}$ close to $-70^{\circ} \mathrm{C}$. PRic $\mathrm{Tg}$ values follow the Fox-Flory law (see equation 4) with respect to molecular weights (see Figure SI-3, in Supporting Information). ${ }^{37}$

$$
T_{g}=T_{g, \infty}-\frac{K}{M n} \quad \text { Eq. } 4
$$

with, $\mathrm{T}_{g, \infty}$ is the maximum glass transition temperature that can be reached at a theoretical infinite molecular weight and $\mathrm{K}$ a parameter related to the contribution of the chain-end to the free volume. For PRic, experimental Tg fits with the following values: $\mathrm{T}_{\mathrm{g}, \infty}=-66{ }^{\circ} \mathrm{C}$ and $\mathrm{K}=4 \cdot 1 \cdot 10^{4} \mathrm{~g} \cdot \mathrm{mol}^{-1}$. In the case of PHS, no effect of the molecular weight on the $\mathrm{T}_{\mathrm{g}}$ was observed since the glass transition is controlled by the crystal phase.

\section{Impact of PRic molar masses on its melt rheological behavior}

As expected, PRic viscosity depends on its molecular weight. Indeed, at room temperature, PRic$1\left(\mathrm{M}_{\mathrm{w}}=6100 \mathrm{~g} \cdot \mathrm{mol}^{-1}\right)$ behaves as a viscous liquid while PRic-5 $\left(\mathrm{M}_{\mathrm{w}}=131000 \mathrm{~g} \cdot \mathrm{mol}^{-1}\right)$ does not flow at short time scale and appears as a viscoelastic solid. This observation suggests a strong effect of the molecular weight on the rheological properties of polyricinoleate. This effect can be quantified through the measurement of $\eta_{0}$, the Newtonian viscosity. 
As it was established by Fox and Flory ${ }^{38}$, the viscosity of a polymer is strongly related to its molecular weight. This relationship varies whether the polymer is entangled or not, according to equation 5 and equation 6.

$$
\begin{array}{ll}
\log \eta_{0}=\log M w+A \text { for } M<M_{c} & \text { Eq. } 5 \\
\log \eta_{0}=3.4 \log M w+B \text { for } M>M_{c} & \text { Eq. } 6
\end{array}
$$

where $\eta_{0}$ is the Newtonian viscosity and $M_{c}$ the critical molecular weight of entanglement. $A$ and $B$ are empirical constants dependent on the nature of the polymer and the temperature.

By rheometry analysis (see Supporting Information), Newtonian viscosities at $20^{\circ} \mathrm{C}$ was determined for a new PRic series with Mw ranging from 5000 to 130000 g.mol ${ }^{-1}$, and plotted as a function of the PRic molecular weight (see Figure 4, and Table 4).

\begin{tabular}{|c|c|c|c|c|}
\hline Entry & $\mathrm{M}_{\mathrm{n}}{ }^{1}\left(\mathrm{~g} \cdot \mathrm{mol}^{-1}\right)$ & $\mathrm{M}_{\mathrm{w}}^{1}\left(\mathrm{~g} \cdot \mathrm{mol}^{-1}\right)$ & $\mathbf{D}^{1}$ & $\eta_{0} 20^{\circ} \mathrm{C}$ (Pa.s) ${ }^{2}$ \\
\hline PRic-6 & 3000 & 5000 & 1.7 & $6.9 \pm 0.5$ \\
\hline PRic-7 & 8000 & 18000 & 2.2 & $28.81 \pm 0.028$ \\
\hline PRic-8 & 11000 & 31000 & 2.8 & $872 \pm 3.7$ \\
\hline PRic-9 & 15000 & 92000 & 6.1 & $2.6010^{5} \pm 6.410^{3}$ \\
\hline PRic-10 & 28000 & 131500 & 4.6 & $8.5310^{5} \pm 8.210^{4}$ \\
\hline \multicolumn{5}{|c|}{$\begin{array}{l}1 \text { Obtained by SEC in THF - triple detection, dn/dc values used for } \\
\text { calculation }\end{array}$} \\
\hline \multicolumn{5}{|c|}{$\begin{array}{l}2 \text { See Supporting Information for more information about the determination } \\
\text { of } \eta_{0}\end{array}$} \\
\hline
\end{tabular}

Table 4: Molecular weights and melt Newtonian viscosity at $20^{\circ} \mathrm{C}$ 


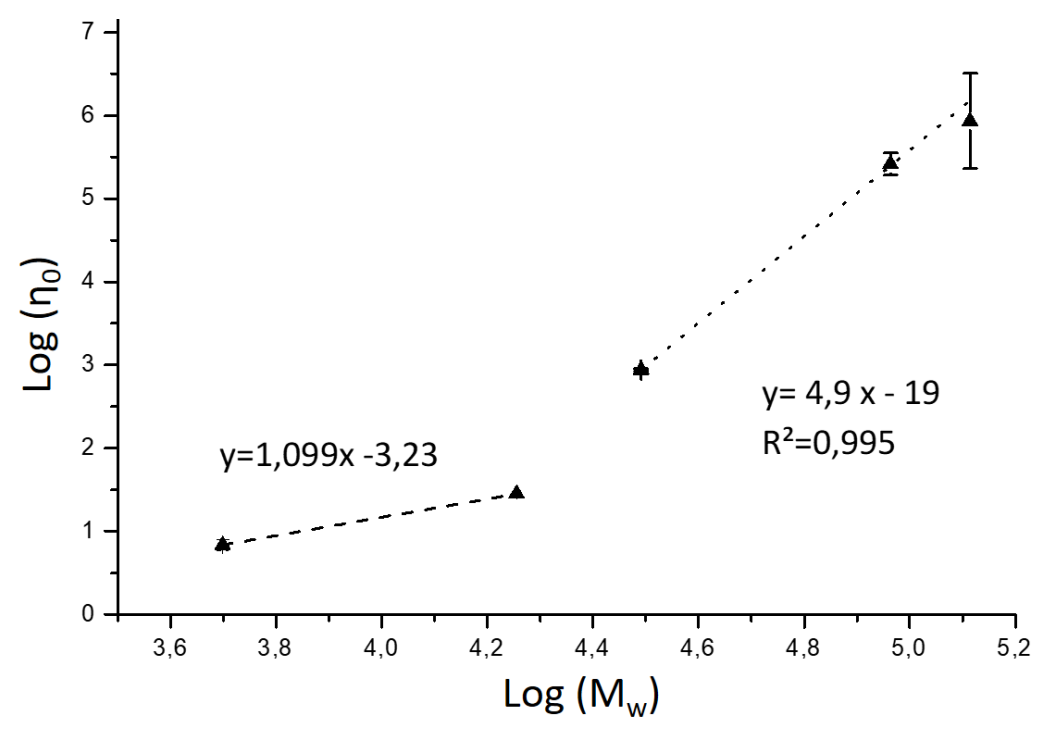

Figure 4: Log-log plot of the Newtonian viscosity versus molar mass for PRic samples at $20{ }^{\circ} \mathrm{C}$

As expected, $\eta_{0}$ increases with the PRic molecular weight, from 6.87 Pa.s $\left(5000\right.$ g.mol $\left.{ }^{-1}\right)$ to $8.5310^{5}$ Pa.s (131500 g. $\left.\mathrm{mol}^{-1}\right)$. A slope rupture is clearly observed for $\log \left(\mathrm{M}_{\mathrm{w}}\right) \approx 4.3$ corresponding to molar weight around $\mathrm{M}_{\mathrm{w}}=25000 \mathrm{~g} \cdot \mathrm{mol}^{-1}$. For $\mathrm{M}_{\mathrm{w}}<25000 \mathrm{~g} \cdot \mathrm{mol}^{-1}$, a slope of 1 is obtained suggesting that the chains are disentangled (PRic-6 and PRic-7) and probably present Rouse relaxation mode. For $\mathrm{M}_{\mathrm{w}}>25000 \mathrm{~g} \cdot \mathrm{mol}^{-1}$, a slope around 4.9 is obtained. This is superior to the theoretical value for entangled polymer chains, i.e. 3.4. whose dynamic is governed by reptation. The large dispersity of PRic-9 $(Đ=6.1)$ and PRic-10 $(Đ=4.6)$ could explain the discrepancy between the experimental and the theoretical value of 3.4. Indeed, it is reported that dispersity has an impact on the rheological behavior of the polymer chains and, consequently, on the sample viscosity. ${ }^{39,40}$ However, as reported in the literature, this effect implies variation from 3.3 to $3.7 .{ }^{41-43}$ There is also probably an impact of the pendant alkyl segments along the polymer backbone (comb-like structure). ${ }^{40,44}$

Towards promising viscosity modifiers 
All the so-formed PRic and PHS were then tested as additives in a mineral oil (MO) and an organic triglyceride oil (OTO) to be evaluated as viscosity modifiers for lubricants. A concentration of 3 wt.\% was fixed. As reported in Table 2, the PRic with the highest molecular weights are not soluble in the oils: PRic-3 to 5 for MO, PRic-4 and 5 for OTO. Surprisingly, polyhydroxystearate is perfectly soluble in both oils, whatever the molecular weights. Only the oils containing soluble PRics of PHS as additives were then analyzed by viscosimetry. The kinematic viscosity of the mixtures was measured from $20^{\circ} \mathrm{C}$ to $100{ }^{\circ} \mathrm{C}$ allowing determining the relative viscosity and the Viscosity Indexes. The relative viscosity versus the temperature is displayed in Figure 5 and the kinematic viscosities, the VI as well as the Q values are reported in Table 5. Their values were compared to two commercial additives, Ref-O, specific for the organic oil and Ref-M, specific for the mineral one.
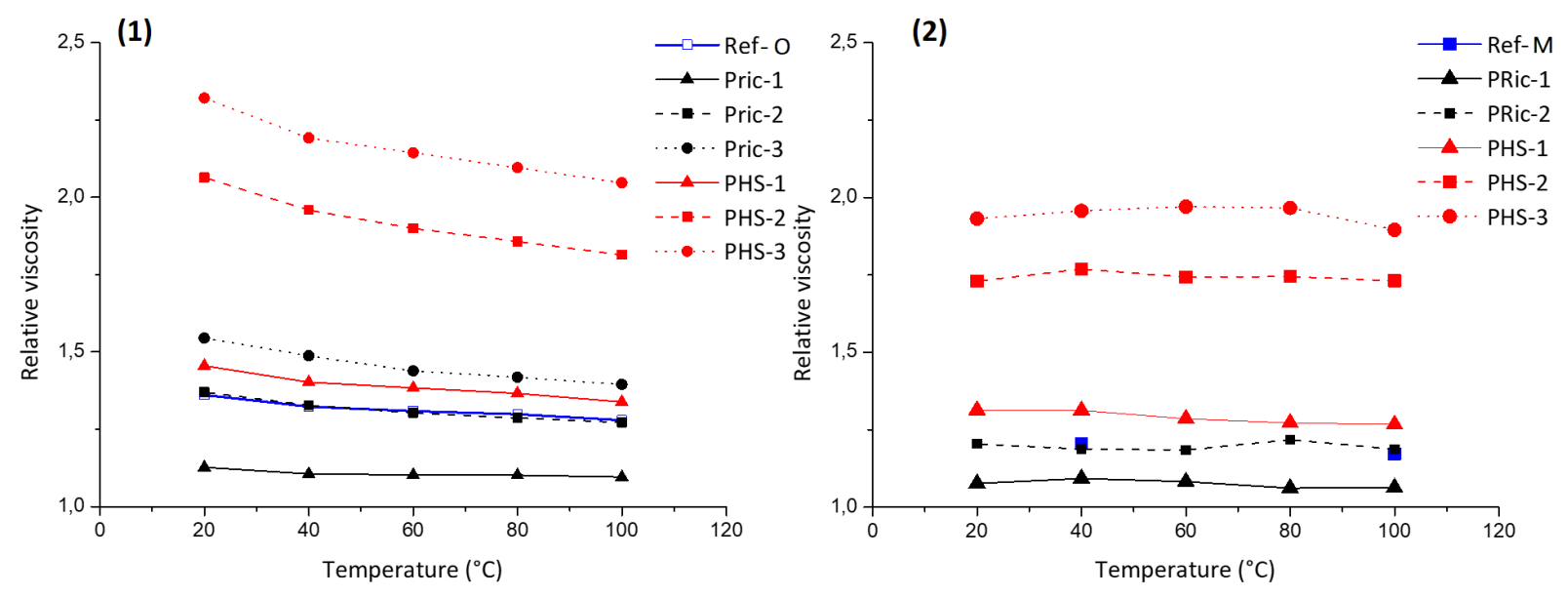

Figure 5: Relative viscosities of several PRic, PHS and commercial additives blended at 3 wt.\% in (1) organic oil and (2) mineral oil regarding the temperature between $20^{\circ} \mathrm{C}$ and $100{ }^{\circ} \mathrm{C}$.

The most significant impact on the relative viscosity is related to the polymer molecular weights. The highest the molecular weight, the highest the relative viscosity. The PHS-3 with a $\mathrm{M}_{\mathrm{w}}=80$ 
kg.mol ${ }^{-1}$ shows the best thickening properties with an increase of the kinematic viscosity from 20 $\mathrm{mm}^{2} \cdot \mathrm{s}^{-1}$ to $45 \mathrm{~mm}^{2} \cdot \mathrm{s}^{-1}$ in OTO and from $19 \mathrm{~mm}^{2} \cdot \mathrm{s}^{-1}$ to $37 \mathrm{~mm}^{2} \cdot \mathrm{s}^{-1}$ in $\mathrm{MO}$ at $40{ }^{\circ} \mathrm{C}$ for $3 \mathrm{wt} . \%$ blend. These results point out that high molecular weight PHS is a promising thickener in both oils tested. The addition of a polymer additive in OTO induced a decrease of the relative viscosity with the temperature. This phenomenon is observed for all the polyesters tested, independently of their chemical composition and molecular weight leading to value of $\mathrm{Q}$ below 1 testifying that thickening power of the additive is less significant at $100^{\circ} \mathrm{C}$ than at $40^{\circ} \mathrm{C}$. In the case of PHS, a slight increase of $\mathrm{Q}$ was observed with the molecular weight, while the $\mathrm{Q}$ values tend to decrease with PRic molecular weights. However, the Viscosity Index is significantly increased by the addition of a polymer additive in the oil. Even the blend with the lowest molecular weight PRic led to a significant VI increase from 152 to 163 . In these conditions, whatever PHS molecular weight, the Viscosity Index is better than with the commercial additive tested. A maximum of VI $=204$ is obtained for the oil blended with PHS-3 corresponding to a VI increase of +52 . All these results demonstrate that PHS-3 could also be used as a Viscosity Index improver of OTO.

For MO, the $\mathrm{Q}$ values appears to increase with the molecular weights with values close to 1 for PRic-2 $(\mathrm{Q}=0.99)$ and PHS-3 $(\mathrm{Q}=0.94)$. These indicate a more stable viscosity with temperature which leads to better VI with less increase in the kinematic viscosity. For example, in the case of PRic-2, same VI were obtained for OTO and MO but in the first case kinematic viscosity at $40^{\circ} \mathrm{C}$ is increased by $33 \%$ compared to only $19 \%$ for MO. 
a

Table 5: Kinematic viscosity, $\mathrm{KV}$, at 40 and $100{ }^{\circ} \mathrm{C}$ VI and $\mathrm{Q}$ values of OTO and MO blended with 3 wt.\% of commercial additives, PRic and PHS polymers.

\begin{tabular}{c|cccc|cccc}
\hline & \multicolumn{4}{|c|}{ At 3wt\% in OTO } & \multicolumn{5}{c}{ At 3wt\% in MO } \\
\hline & KV & KV & VI & Q & KV & KV & VI & Q \\
& $40^{\circ} \mathrm{C}$ & $100^{\circ} \mathrm{C}$ & & & $40^{\circ} \mathrm{C}$ & $100^{\circ} \mathrm{C}$ & & - \\
\hline None & 20.55 & 4.67 & 152 & - & 18.71 & 4.34 & 145 & - \\
\hline Ref & 27.19 & 5.98 & 175 & 0.87 & 22.55 & 5.08 & 163 & 0.84 \\
\hline PRic-1 & 22.73 & 5.12 & 163 & 0.90 & 20.45 & 4.61 & 147 & 0.69 \\
PRic-2 & 27.29 & 5.94 & 172 & 0.83 & 22.23 & 5.15 & 172 & 0.99 \\
PRic-3 & 30.57 & 6.52 & 175 & 0.81 & - & - & - & - \\
\hline PHS-1 & 28.82 & 6.25 & 176 & 0.84 & 24.56 & 5.49 & 171 & 0.85 \\
PHS-2 & 40.24 & 8.47 & 195 & 0.85 & 33.1 & 7.51 & 205 & 0.93 \\
PHS-3 & 45.05 & 9.56 & 204 & 0.88 & 36.62 & 8.22 & 209 & 0.94 \\
\hline
\end{tabular}

\section{Conclusion}

Polyricinoleate and polyhydroxystearate were synthesized using $\mathrm{Ti}(\mathrm{O} i \mathrm{Pr}) 4$ as a catalyst within a large range of molecular weights, from $\mathrm{M}_{\mathrm{w}}=3 \mathrm{~kg} \cdot \mathrm{mol}^{-1}$ up to $\mathrm{M}_{\mathrm{w}}=130 \mathrm{~kg} \cdot \mathrm{mol}^{-1}$ in the case of PRic. The obtained PHS appeared to be semi-crystalline with a melting point around $-20^{\circ} \mathrm{C}$ while PRic was amorphous with a glass transition temperature around $-70{ }^{\circ} \mathrm{C}$ due to the presence of an internal unsaturation in its backbone. The PRic rheological behavior was evaluated as a function of its molecular weight. It appears that, for low $\mathrm{M}_{\mathrm{w}}$, PRic behaves as a viscous material. Above $\mathrm{M}_{\mathrm{w}}=25 \mathrm{~kg} \cdot \mathrm{mol}^{-1}$, its melt viscosity increases drastically due to the formation of entanglements.

Finally, PRic and PHS have been tested as viscosity modifiers. Contrary to PHS, due to a lack of solubility for the highest molecular weights, only PRic with $\mathrm{M}_{\mathrm{w}} \leq 10 \mathrm{~kg} \cdot \mathrm{mol}^{-1}$ and $\mathrm{M}_{\mathrm{w}} \leq 32$ kg. $\mathrm{mol}^{-1}$ could be tested in mineral and organic oil, respectively. Both PRic and PHS have a 
thickening effect in oil, but PHS with $\mathrm{Mw}=80 \mathrm{~kg} \cdot \mathrm{mol}^{-1}$ showed particularly good thickening efficiency by doubling the viscosity of both OTO and MO and by increasing the Viscosity index about +52 and +64 , respectively. As a result, the bio-based PHS with high molecular weights could be considered as promising viscosity modifiers for more environmentally friendly lubricant applications.

\section{Supporting Information.}

The following files are available free of charge: NMR of PHS, SEC traces of PRic and PHS, rheology methodology and results..

\section{Corresponding Author}

* henri.cramail@enscbp.fr etienne.grau@enscbp.fr

\section{Author Contributions}

The manuscript was written through contributions of all authors. All authors have given approval to the final version of the manuscript. HM performed the experiments, JFLM performed the rheology analysis.

\section{ACKNOWLEDGMENT}

This work was performed, in partnership with the SAS PIVERT, within the frame of the French Institute for the Energy Transition (Institut pour la Transition Energétique (ITE) P.I.V.E.R.T. (www.institut-pivert.com) selected as an Investment for the Future (“Investissements d'Avenir"). This work was supported, as part of the Investments for the Future, by the French Government under the reference ANR-001-01. The authors thank Equipex Xyloforest ANR-10-EQPX-16. The 
financial support from the CPER CAMPUSB project funded by the French state and the Région Nouvelle Aquitaine is gratefully acknowledged.

\section{REFERENCES}

1 Gandini, A. The irruption of polymers from renewable resources on the scene of macromolecular science and technology. Green Chem., 2011, 13, 1061-1083. DOI 10.1039/C0GC00789G

2 Maisonneuve, L.; Lebarbé, T.; Grau, E.; Cramail, H. Structure-properties relationship of fatty acid-based thermoplastics as synthetic polymer mimics. Polym. Chem., 2013, 4, 5472-5517. DOI 10.1039/C3PY00791J

3 Gandini, A.; Lacerda, T. M. Polymers from Plant Oils, John Wiley \& Sons Inc, 2018.

4 Mubofu, E. B. Castor oil as a potential renewable resource for the production of functional materials. Sustain. Chem. Process., 2016, 4, 11. DOI 10.1186/s40508-016-0055-8

5 Gandini, A.; Lacerda, T. M.; Carvalho, A. J. F.; Trovatti, E. Progress of Polymers from Renewable Resources: Furans, Vegetable Oils, and Polysaccharides, Chem. Rev., 2016, 116, 1637-1669. DOI 10.1021/acs.chemrev.5b00264

6 Mutlu, H.; Meier, M. A. R. Castor oil as a renewable resource for the chemical industry. Eur. J. Lipid Sci. Technol., 2010, 112, 10-30. DOI 10.1002/ejlt.200900138

7 Kunduru, K.R.; Basu, A.; Haim Zada, M.; Domb, A.J. Castor Oil-Based Biodegradable Polyesters, Biomacromolecules, 2015, 16, 2572-2587 DOI 10.1021/acs.biomac.5b00923 
8 Vilela, C.; Sousa, A.F.; Fonseca, C.; Serra, A.C.; Coelho, J.F.J.; Freire, C.S.R.; Silvestre, A.J.D. The quest for sustainable polyesters - insights into the future, Polym. Chem., 2014, 5, 31193141 DOI 10.1039/C3PY01213A

9 Teomim, D.; Nyska, A.; Domb,A.J. Ricinoleic acid-based biopolymers, J. Biomed. Mater. Res., 1999, 45, 258-267 DOI 10.1002/(SICI)1097-4636(19990605)45:3<258::AID$\mathrm{JBM} 14>3.0 . \mathrm{CO} ; 2-\mathrm{W}$

10 García-Zapateiro, L.A.; Franco, J.M.; Valencia, C.; Delgado M.A.; Gallegos, C., Viscous, thermal and tribological characterization of oleic and ricinoleic acids-derived estolides and their blends with vegetable oils, J. Ind. Eng. Chem., 2013, 19, 1289-1298 DOI 10.1016/j.jiec.2012.12.030

11 Slivniak, R.; Domb, A.J., Lactic Acid and Ricinoleic Acid Based Copolyesters, Macromolecules, 2005, 38, 5545-5553 DOI 10.1021/ma0503918

12 Lebarbé, T.; Ibarboure, E.; Gadenne, B.; Alfos C.; Cramail, H., Fully bio-based poly(1lactide)-b-poly(ricinoleic acid)-b-poly(l-lactide) triblock copolyesters: investigation of solid-state morphology and thermo-mechanical properties, Polym. Chem., 2013, 4, 3357-3369 DOI 10.1039/C3PY00300K

13 Ebata, H.; Toshima, K.;Matsumura, S., Lipase-catalyzed synthesis and curing of highmolecular-weight polyricinoleate, Macromol. Biosci., 2007, 7, 798-803 DOI 10.1002/mabi.200700018

14 Ebata, H.; Yasuda, M.; Toshima K.; Matsumura, S., Poly (Ricinoleic Acid) Based Novel Thermosetting Elastomer, J. Oleo Sci., 2008, 57, 315-320 DOI 10.5650/jos.57.315 
15 Dworakowska, S.; Le Coz, C.; Chollet, G.; Grau, E.; Cramail, H., Cross-Linking of Polyesters Based on Fatty Acids, Eur. J. Lipids Sci. Tech., 2019, 121, 1900264 DOI 10.1002/ejlt.201900264

16 Ghosh, P.; Hoque, M.; Karmakar, G., Castor oil as potential multifunctional additive in the formulation of eco-friendly lubricant, Polym. Bull., 2018, 75, 501-514 DOI 10.1007/s00289-017$2047-6$

17 Mortier, R.M.; Fox M.F.; Orszulik, S.T., Chemistry and Technology of Lubricants, Springer, 2010.

18 Martini, A.; Ramasamy, U.S.; Len, M., Review of Viscosity Modifier Lubricant Additives, Tribol. Lett., 2018, 66, 58 DOI 10.1007/s11249-018-1007-0

19 Rudnick, L. R., Lubricant Additives: Chemistry and Applications, Taylor and Francis, 2017.

20 Rizvi, S. Q. A., A Comprehensive Review of Lubricant Chemistry, Technology, Selection and Design, ASTM International, 2009.

21 Pirro, D. M.; Webster, M.; Daschner, E., Lubrication Fundamentals, Third edition, CRC Press, 2016.

22 Shylesh, S.; Gokhale, A.A.; Ho, C.R.; Bell, A.T., Novel Strategies for the Production of Fuels, Lubricants, and Chemicals from Biomass, Acc. Chem. Res., 2017, 50, 2589-2597 DOI 10.1021/acs.accounts. $7 \mathrm{~b} 00354$ 
23 Mobarak, H.M.; Niza Mohamad, E.; Masjuki, H.H.; Kalam, M.A.; Al Mahmud, K.A.H.; Habibullah, M.; Ashraful, A.M. The prospects of biolubricants as alternatives in automotive applications, Renew. Sustain. Energy Rev., 2014, 33, 34-43, DOI 10.1016/j.rser.2014.01.062

24 Panchal, T.M.; Patel, A.; Chauhan, D.D.; Thomas M.; Patel, J.V., A methodological review on bio-lubricants from vegetable oil based resources, Renew. Sustain. Energy Rev., 2017, 70, 6570 DOI 10.1016/j.rser.2016.11.105

25 Biresaw, G.; Sharma, B.K., Environmentally friendly and biobased lubricants, Taylor and Francis, 2017.

26 Davim, J. P., Ecotribology, Springer, 2016.

29 ASTMInternational D2270-10, in Annual Book of ASTM Standards, 2015.

30 Rogers M. E.; Long, T. E., Synthetic Methods in Step-Growth Synthetic Methods in StepGrowth, Wiley-Interscience, 2003.

31 Testud, B.; Pintori, D.; Grau, E.; Taton D.; Cramail, H., Hyperbranched polyesters by polycondensation of fatty acid-based ABn-type monomers, Green Chem., 2017, 19, 259-269 DOI 10.1039/C6GC02294D

32 Kasmi, N.; Majdoub, M.; Papageorgiou, G.Z.; Achilias, D.S.; Bikiaris, D.N., Solid-State Polymerization of Poly(ethylene furanoate) Biobased Polyester, I: Effect of Catalyst Type on Molecular Weight Increase, Polymers (Basel)., 2017, 9, 607 DOI 10.3390/polym9110607

33 Park, S.S.; Im, S.S.; Kim, D.K., Kinetics for the catalyzed formation of poly(ethylene 2,6naphthalate) (PEN) by various metal compounds, J. Polym. Sci. Part A Polym. Chem., 1994, 32, 2873-2881 DOI 10.1002/pola.1994.080321509 
34 Otera, J., Transesterification, Chem. Rev., 1993, 93, 1449-1470 DOI 10.1021/cr00020a004

35 Liu, C.; Liu, F.; Cai, J.; Xie, W.; Long, T.E.; Turner, S.R.; Lyons, A.; Gross, R.A., Polymers from Fatty Acids: Poly( $\omega$-hydroxyl tetradecanoic acid) Synthesis and PhysicoMechanical Studies, Biomacromolecules, 2011, 12, 3291-3298, DOI 10.1021/bm2007554

36 Lebarbé, T.; Grau, E.; Gadenne, B.; Alfos, C.; Cramail, H., Synthesis of Fatty Acid-Based Polyesters and Their Blends with Poly(l-lactide) as a Way To Tailor PLLA Toughness, ACS Sustain. Chem. Eng., 2015, 3, 283-292 DOI 10.1021/sc500648g

37 Fox T.G.; Flory, P.G., Second-Order Transition Temperatures and Related Properties of Polystyrene. I. Influence of Molecular Weight, J. Appl. Phys., 1950, 21, 581-591, DOI $10.1063 / 1.1699711$

38 Fox T.G.; Flory, P.G., Further Studies on the Melt Viscosity of Polyisobutylene, J. Phys. Chem., 1951, 55, 221-234 DOI 10.1021/j150485a010

39 Struglinski M.J.; Graessley, W.W., Effects of polydispersity on the linear viscoelastic properties of entangled polymers. 1. Experimental observations for binary mixtures of linear polybutadiene, Macromolecules, 1985, 18, 2630-2643 DOI 10.1021/ma00154a046

40 Wood-Adams, P.M.; Dealy, J.M.; DeGroot A.M.; Redwine, O.D., Effect of Molecular Structure on the Linear Viscoelastic Behavior of Polyethylene, Macromolecules, 2000, 33, 74897499, DOI 10.1021/ma991533z

41 Cross, M.M., Viscosity, molecular weight and chain entanglement, Polymer (Guildf)., 1970, 11, 238-244 DOI 10.1016/0032-3861(70)90034-0 
42 Colby, R.H.; Fetters, L.J.; Graessley, W.W., The melt viscosity-molecular weight relationship for linear polymers, Macromolecules, 1987, 20, 2226-2237, DOI $10.1021 / \mathrm{ma} 00175 \mathrm{a} 030$

43 Bueche, F., Viscosity, Self-Diffusion, and Allied Effects in Solid Polymers, J. Chem. Phys., 1952, 20, 1959-1964 DOI 10.1063/1.1700349

44 Larson, R.G., Combinatorial Rheology of Branched Polymer Melts, Macromolecules, 2001, 34, 4556-4571 DOI 10.1021/ma000700o 
For Table of Contents Use Only
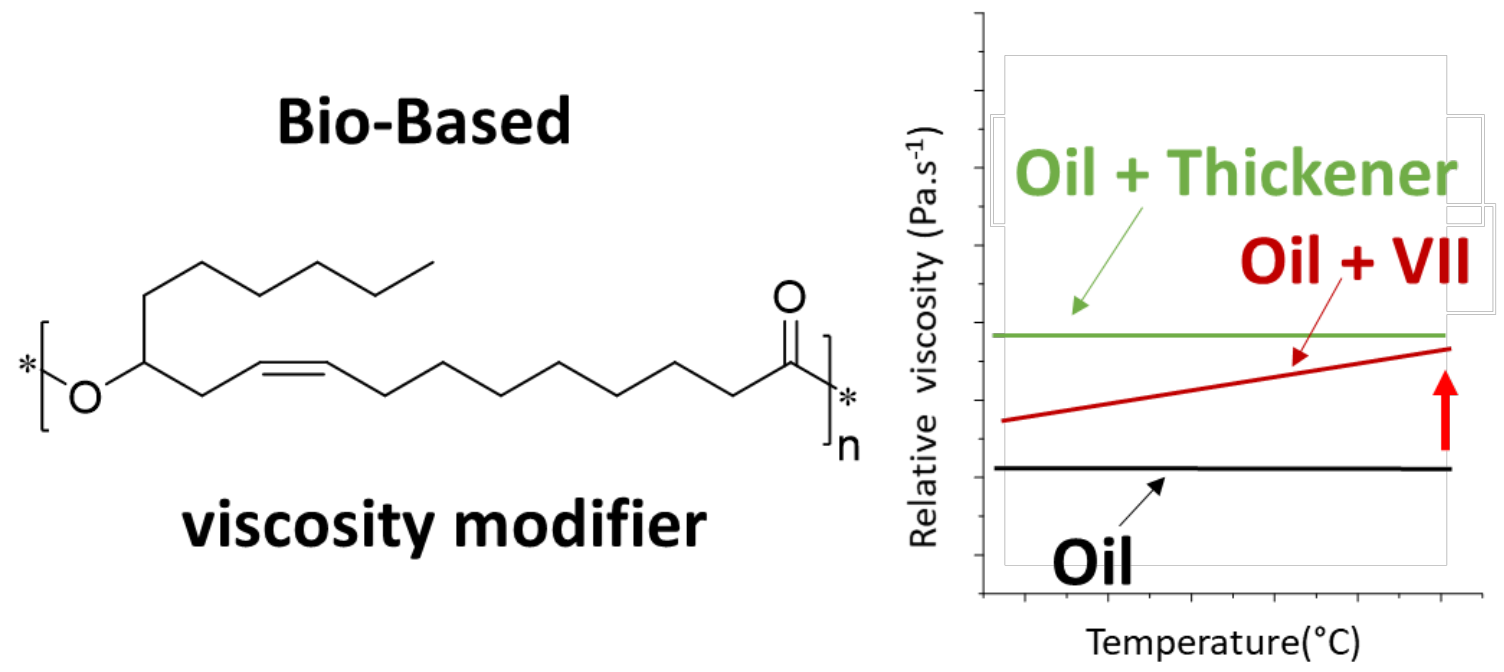

Polyester obtained by self polyesterification of ricinoleate derivatives were synthesized. Their properties in melt and oil solution were investigated in regards to their molecular weights. 


\title{
Bio-based polyricinoleate and polyhydroxystearate: properties and evaluation as viscosity modifiers for lubricants
}

\author{
Hélène Méheust, Jean-François Le Meins, Etienne Grau*, Henri Cramail* \\ Henri.Cramail@enscbp.fr \\ egrau@enscbp.fr
}

Number of pages: 13

Number of Figures: 11

Number of Tables: 2

Figure SI - 1: ${ }^{1} \mathrm{H}$ NMR spectra of (1) methyl-12- hydroxystearate monomer and

(2)polyhydroxystearate in $\mathrm{CDCl}_{3}$

Figure SI - 2: ${ }^{1} \mathrm{H}$ NMR spectra polyricinoleate in $\mathrm{CDCl}_{3}$

Figure $\mathrm{SI}-3:{ }^{1} \mathrm{H}$ NMR spectra of polyhydroxystearate in $\mathrm{CDCl}_{3}$

Figure SI - 4: SEC traces of (1)Polyricinoleate and (2) Polyhydroxystearate. Measurement performed in THF.

Figure SI - 5: PRic glass transition temperature as a function of (1) PRic molar mass $\left(M_{n}\right)$ and (2) $1 / M_{n}$

Figure SI - 6: Translation factor as a function of 1/T according to Andrade law

Figure SI - 7: Complex viscosity as a function of shear strain for a series of PRic with various $\mathrm{M}_{\mathrm{w}}$. Performed at $20^{\circ} \mathrm{C}$ with an angular frequency of $10{\mathrm{rad} . \mathrm{s}^{-1}}^{-1}$

Figure SI - 8: Master curves at $-20^{\circ} \mathrm{C}$ of PRic samples. Reduced storage and loss modulus are expressed versus the reduced angular frequency

Figure SI - 9: Polyricinoleate reduced complex viscosity versus the reduced angular frequency obtained from TTS at $-20^{\circ} \mathrm{C}$ as reference temperature, $1 \%$ shear strain

Figure SI -10: Viscosity versus shear rate obtained by creep measurements. (1) PRic-7 performed at $20{ }^{\circ} \mathrm{C}$, (2) PRic-9 performed at $200{ }^{\circ} \mathrm{C}$ and (3) PRic-10 performed at $150{ }^{\circ} \mathrm{C}$ 
Figure SI-11: Master curves at $80^{\circ} \mathrm{C}$ of PRic-9 and PRic-10 samples. Reduced storage and loss modulus are expressed versus the reduced angular frequency

Table SI-1: Translation factor and actovation energy obtained by TTS master curves at $-20^{\circ} \mathrm{C}$.

Table SI-2: Translation factor and activation energy obtained by TTS master curves at $80^{\circ} \mathrm{C}$ as reference. 


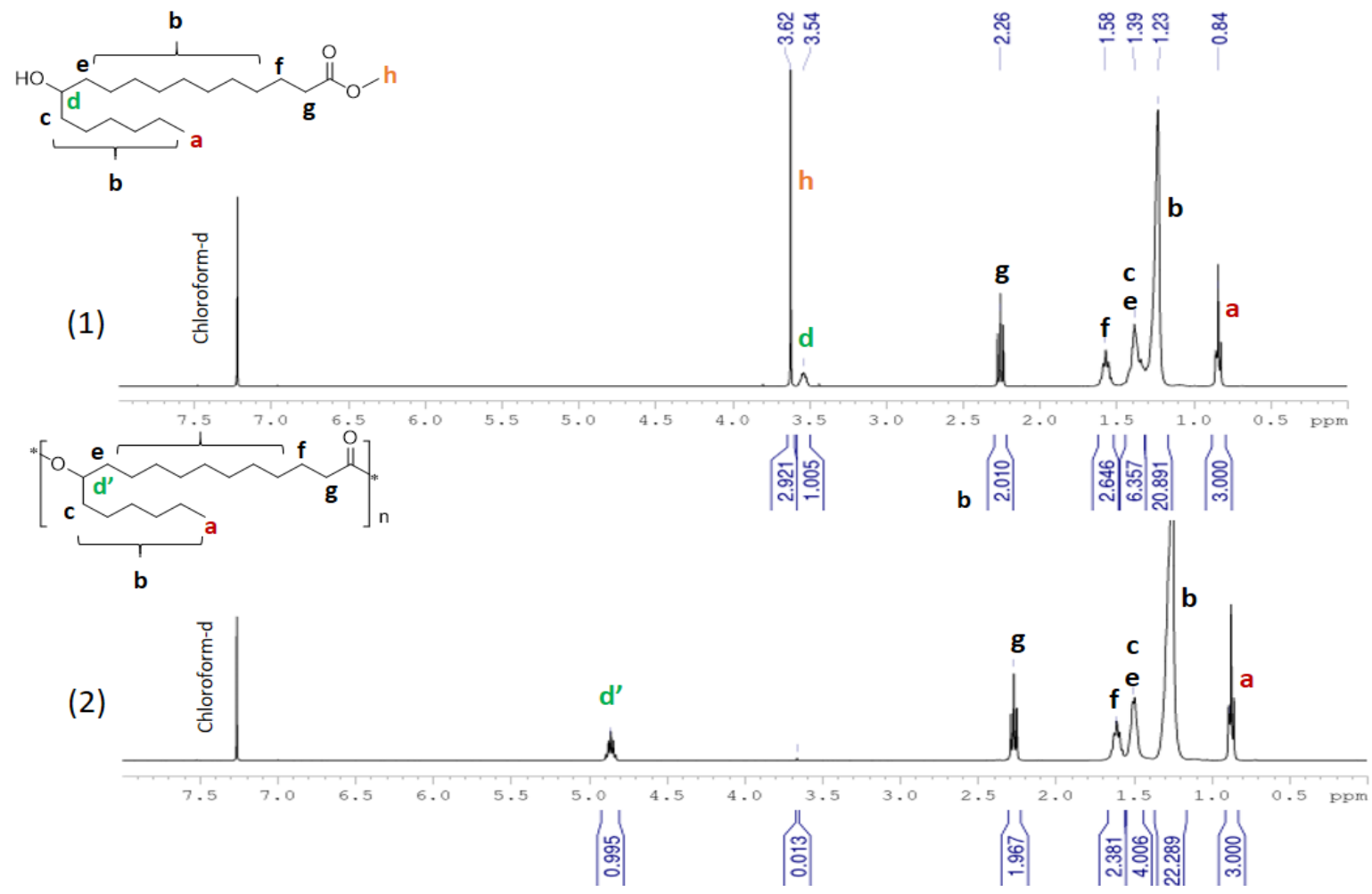

Figure SI - 2: ${ }^{1} \mathrm{H}$ NMR spectra of (1) methyl-12- hydroxystearate monomer and (2)polyhydroxystearate in $\mathrm{CDCl}_{3}$ 


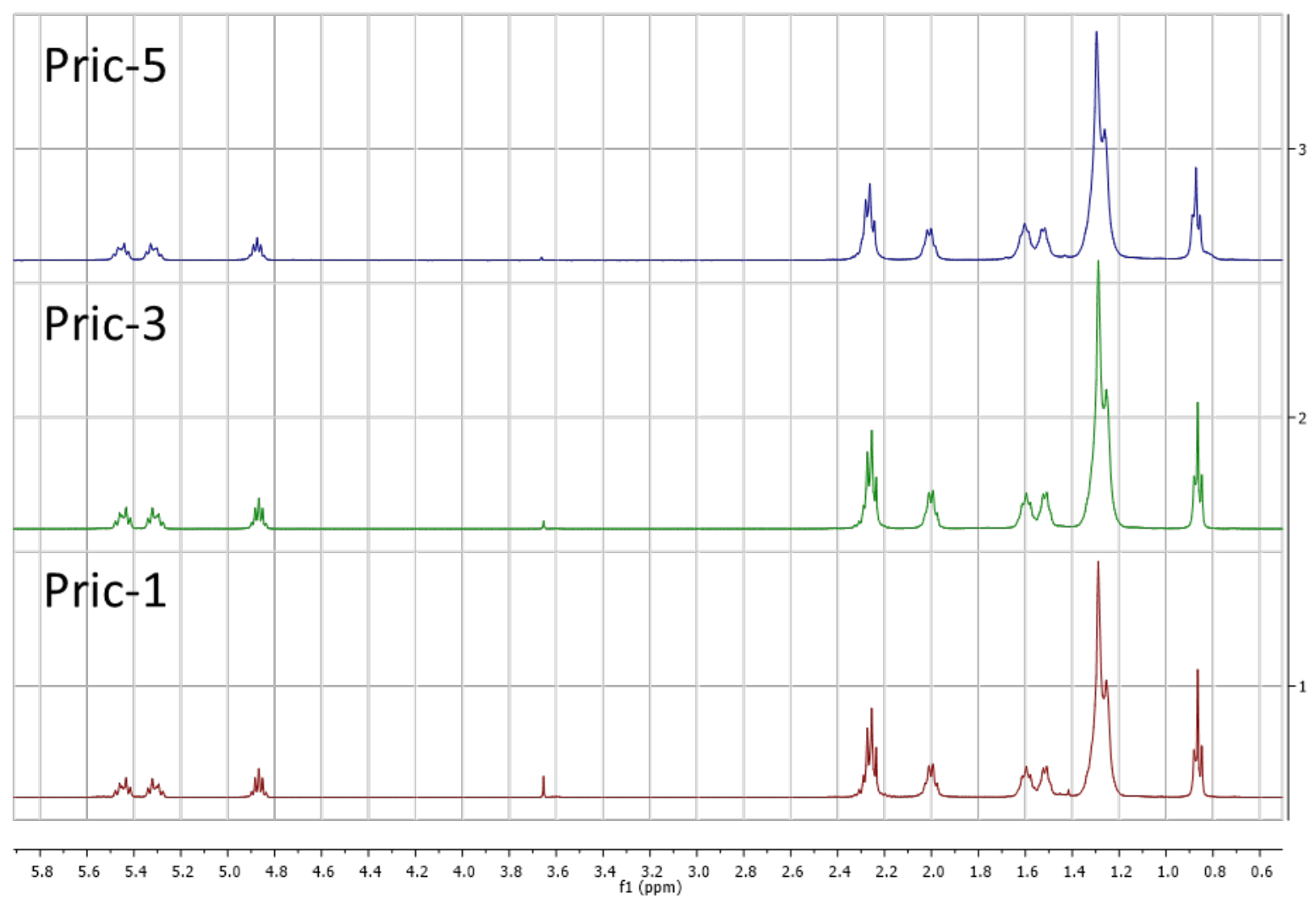

Fig $\mathrm{SI}-2:{ }^{1} \mathrm{H}$ NMR spectra of polyricinoleate in $\mathrm{CDCl}_{3}$

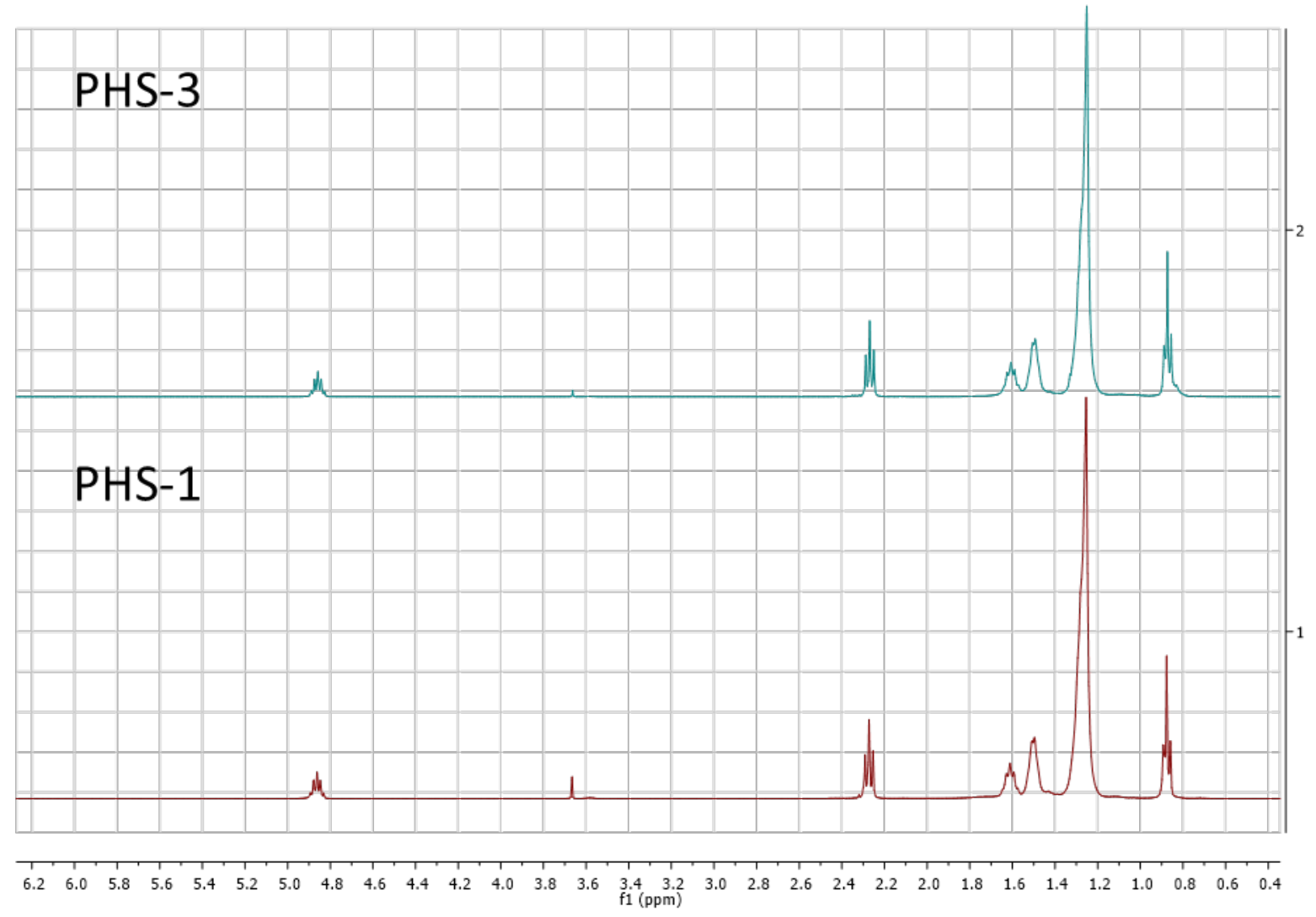

Figure $\mathrm{SI}-3:{ }^{1} \mathrm{H}$ NMR spectra of polyhydroxystearate in $\mathrm{CDCl}_{3}$ 

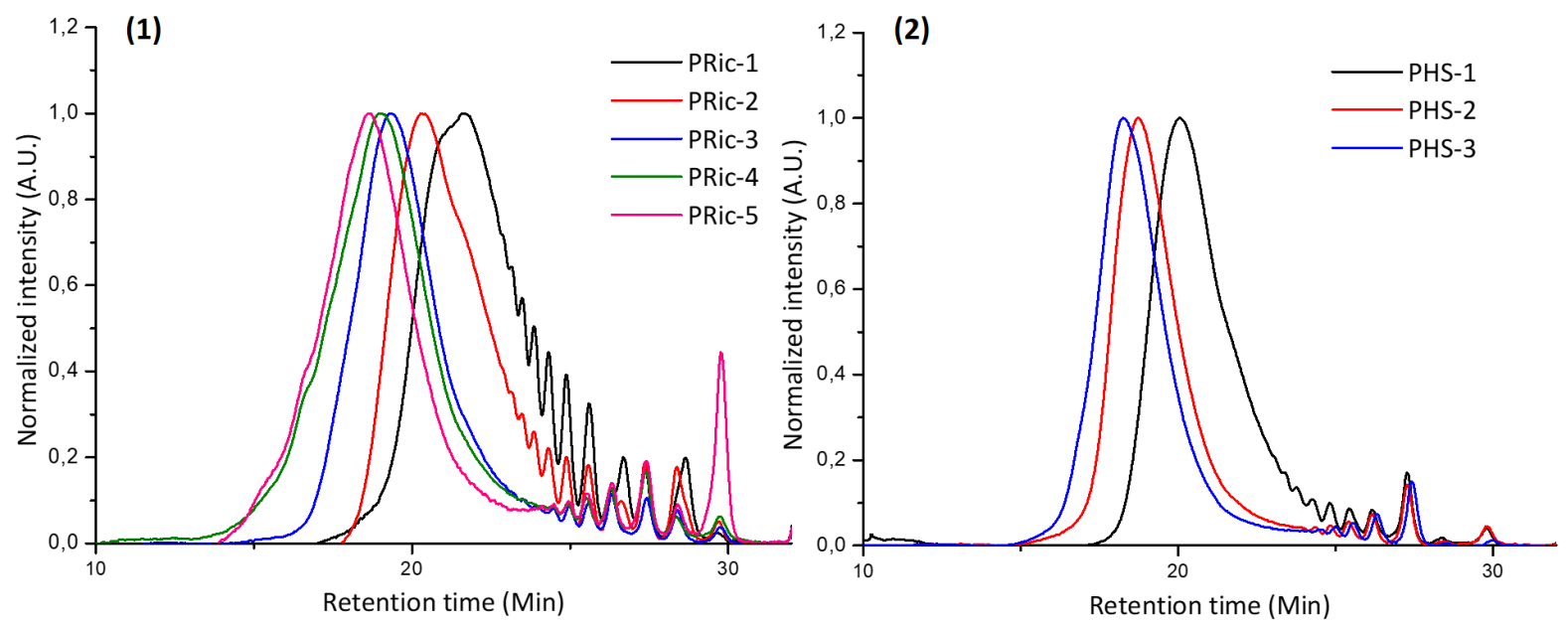

Figure SI - 4: SEC traces of (1)Polyricinoleate and (2) Polyhydroxystearate. Measurement performed in THF.
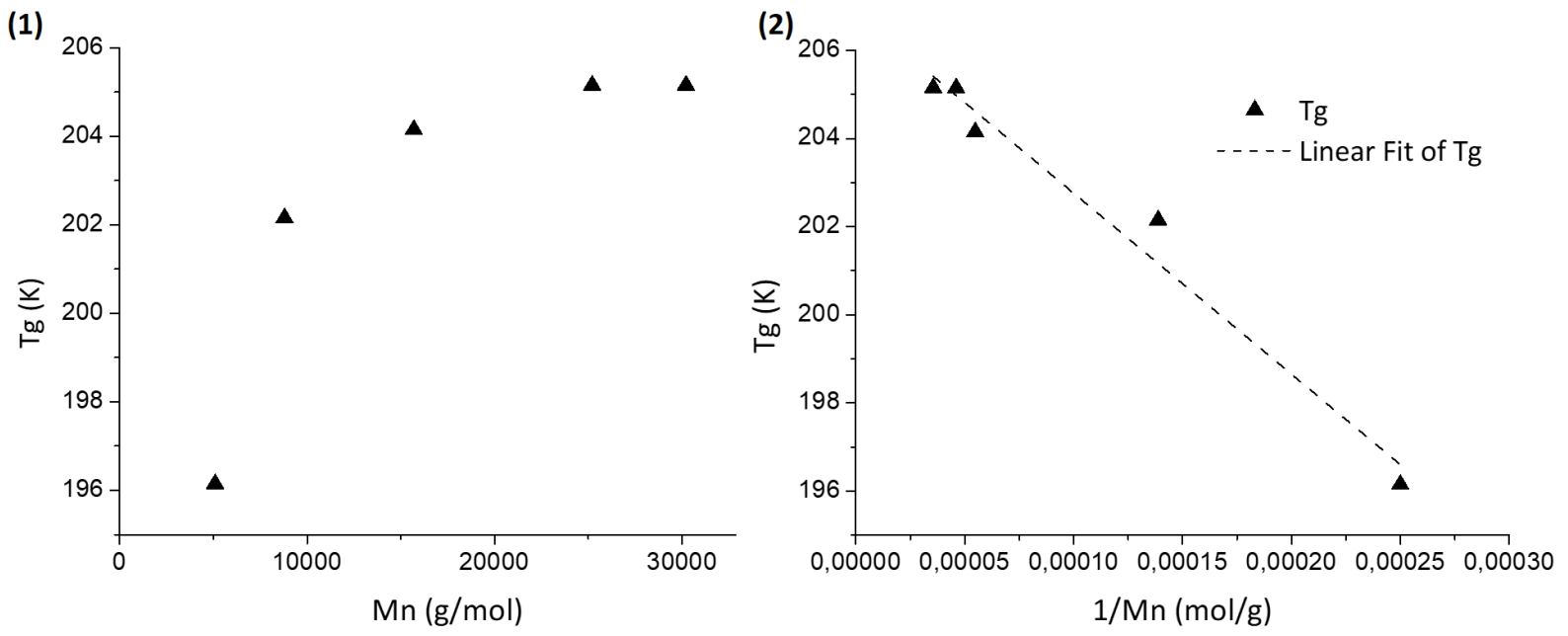

Figure SI - 5: PRic glass transition temperature as a function of (1) PRic molecular weight $\left(\mathrm{M}_{\mathrm{n}}\right)$ and (2) $1 / \mathrm{M}_{\mathrm{n}}$ 


\section{$\underline{\text { Rheometry analysis: }}$}

\section{Methodology}

The objective was to establish the evolution profile of the newtonian viscosity versus molecular weight of the different system at a fixed, reference temperature. Viscosity was estimated through the evaluation of complex viscosity $\eta^{*}$ measured at different temperature, and the establishment of master curves through the use of the Time Temperature Superposition (TTS).

The complex viscosity was calculated with the data obtained from the dynamic shear measurements according to equation $1 .^{1}$

$$
\left|\eta^{*}\right|=\frac{\left|G^{*}\right|}{\omega}=\frac{\sqrt{\left(G^{\prime}\right)^{2}+\left(G^{\prime \prime}\right)^{2}}}{\omega} \quad \text { Eq.1 }
$$

where the elastic modulus G' and the loss modulus G' are given as a function of the angular frequency $\omega$.

According to Cox-Merz Rule, ${ }^{1}$ the dependence of the steady shear viscosity on the shear rate is equal to the dependence of the complex viscosity as a function of frequency. Therefore a plateau of complex viscosity at low angular frequencies reflects the Newtonian viscosity. In some cases, when the plateau value of complex viscosity could not be obtained with the master curves, creep experiments have then been performed to measure the viscosity.

The shift factor $\mathrm{a}_{\mathrm{T}} / \mathrm{Tref}$ used to establish master curves follows an Andrade law ${ }^{1}$ according to Equation 2 , as illustrated in the Figure SI 6

$$
\ln \left(a_{T}\right)=\frac{E_{a}}{R}\left(\frac{1}{T}-\frac{1}{T_{R e f}}\right) \quad \text { Eq. } 2
$$

where $E_{a}$ is the activation energy and $R$ the universal gas constant. By using Andrade law, it is possible to determine the viscosity of the material at another temperature, as, the translation factor $a_{T}$ is correlated to the melt polymer viscosity. ${ }^{2}$ and can be considered as the ratio of viscosity at two different temperature (eq 3 ).

$$
a_{T}=\frac{\eta_{T}}{\eta_{T_{R e f}}} \text { Eq.3 }
$$

Then, the Newtonianviscosities could be estimated at $20^{\circ} \mathrm{C}$ for all the polymers.. 


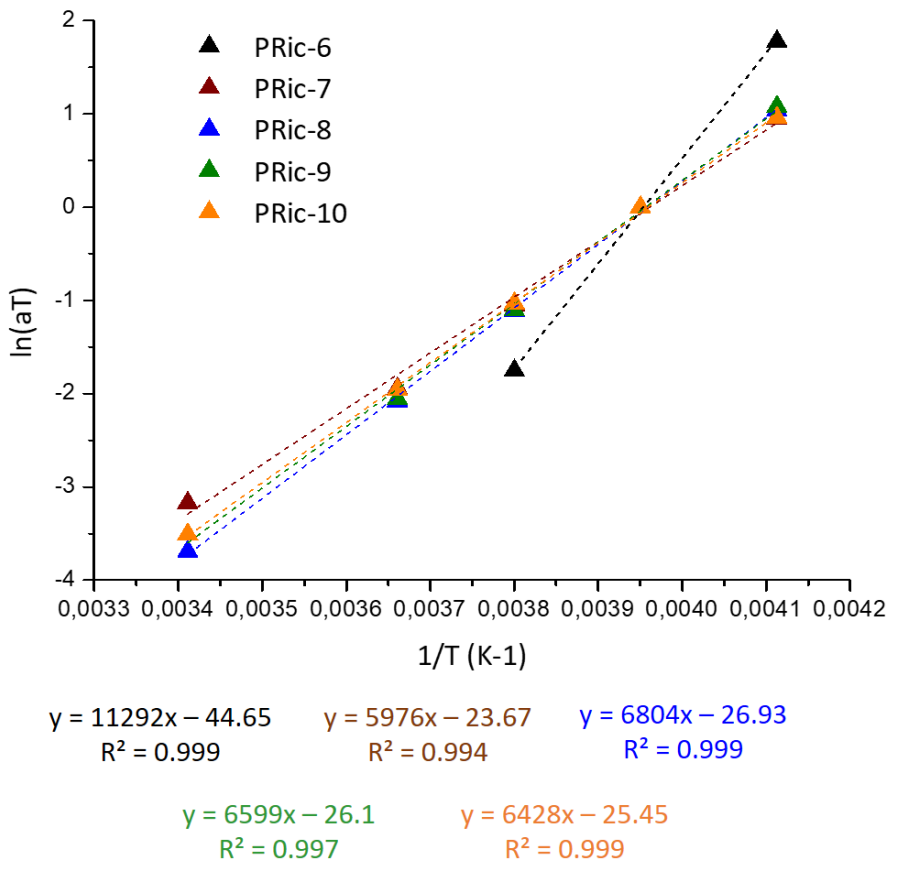

Figure SI - 6: Translation factor as a function of $1 /$ T fitted with Andrade law

\section{Rheology results}

As displayed in Figure SI-7, first the linear domains of PRic with different molecular weights were determined. For all samples, a linear domain was obtained up to a shear strain of $100 \%$. A shear strain of $\gamma=1 \%$ was fixed for the frequency sweep experiments.

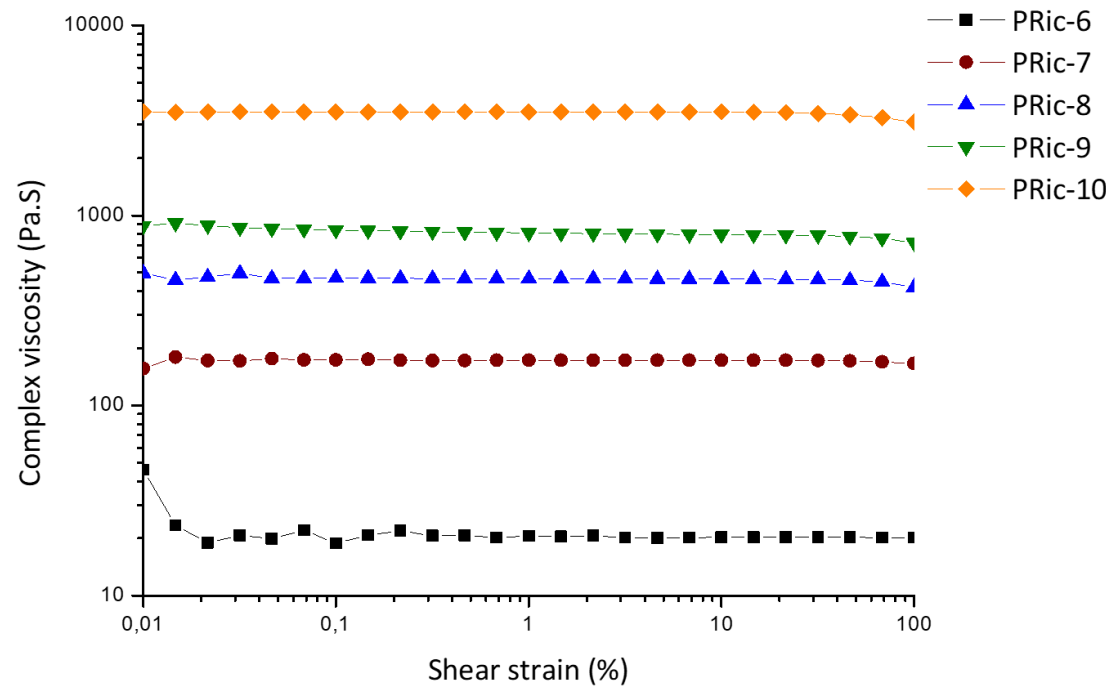

Figure SI - 7: Complex viscosity as a function of shear strain for a series of PRic with various $\mathrm{M}_{\mathrm{w}}$. Performed at $20^{\circ} \mathrm{C}$ with an angular frequency of $10 \mathrm{rad} . \mathrm{s}^{-1}$ 
The rheological properties were evaluated under dynamic frequency sweep (100 rad.s ${ }^{-1}-0.1$ $\operatorname{rad} . \mathrm{s}^{-1}$ ) at different temperature and the time-temperature superposition (TTS) principle was applied. The master curves of elastic and loss moduli obtained for a reference temperature of $20{ }^{\circ} \mathrm{C}$ are plotted in Figure SI-8 

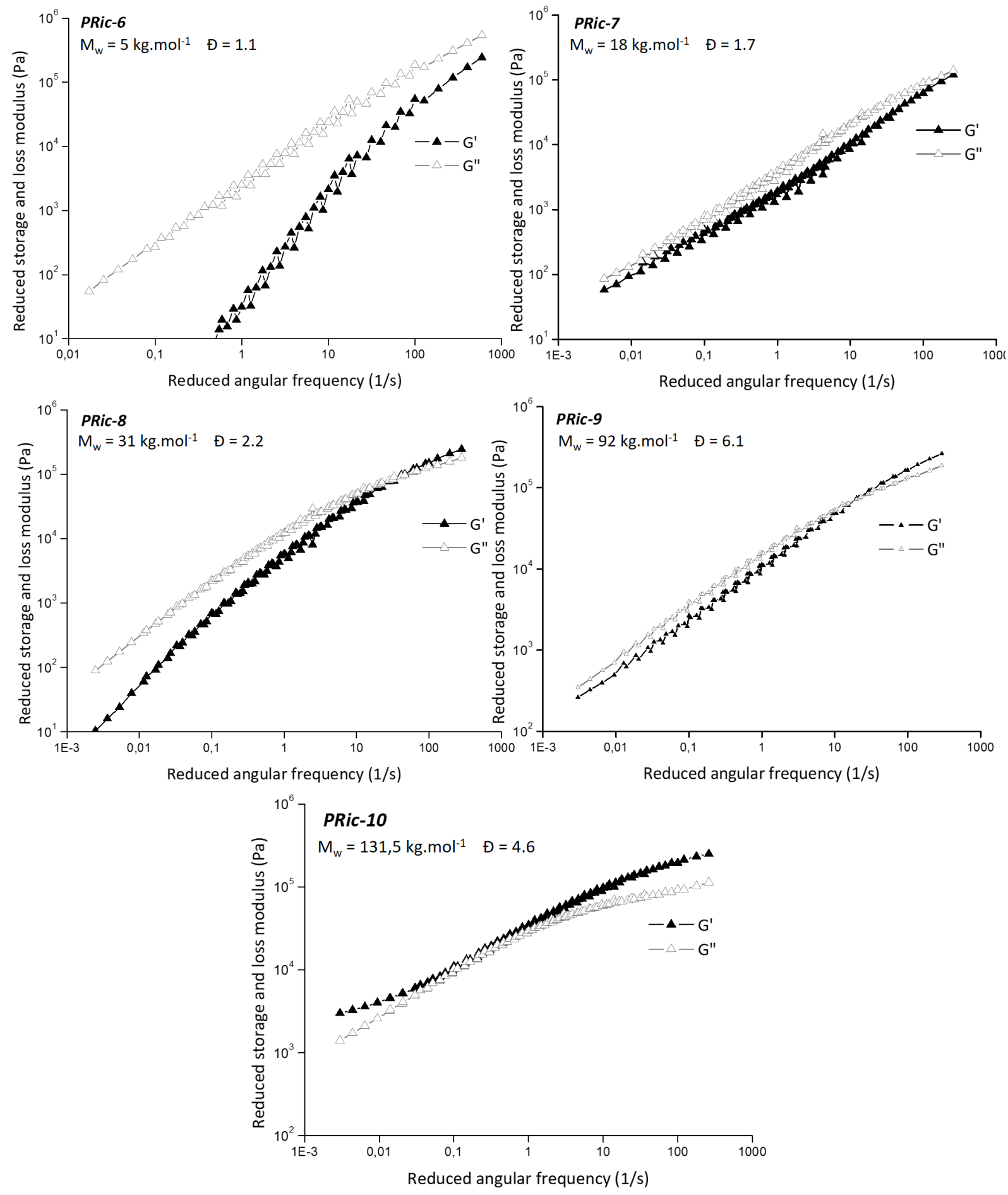

Figure $\mathrm{SI}$ - 8: Master curves at $-20^{\circ} \mathrm{C}$ of PRic samples. storage and loss modulus are expressed versus the reduced angular frequency

From these data, the complex viscosity of the series of PRics were expressed as a function of angular frequency, with $0,003<\omega<294$ rad. $\mathrm{s}^{-1}$ at $-20^{\circ} \mathrm{C}$. Results are plotted in Figure SI-9. 


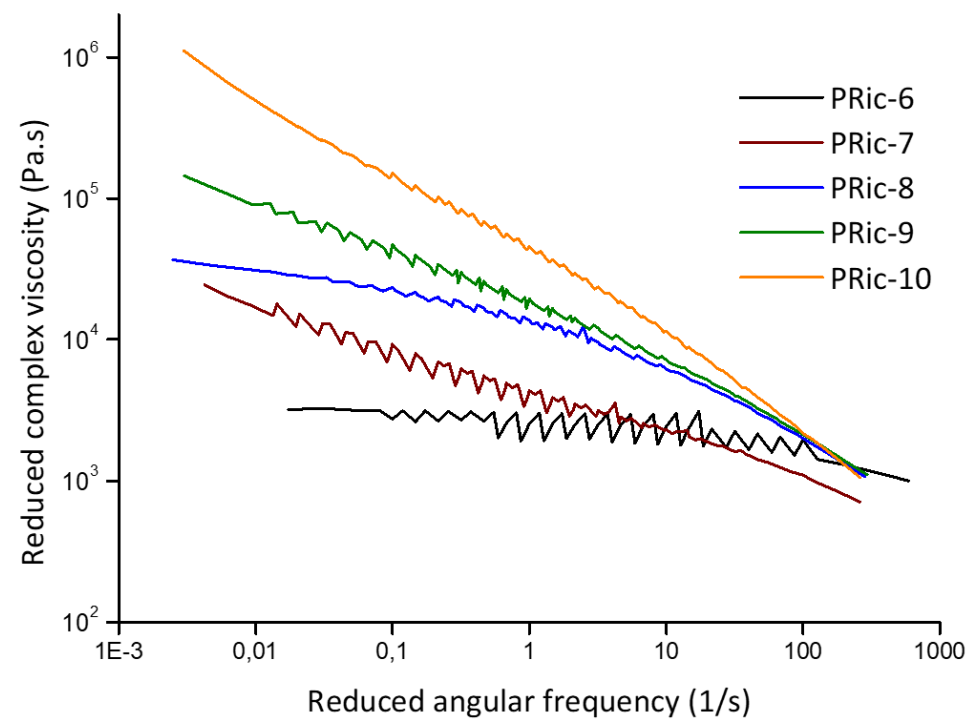

Figure SI - 9: Polyricinoleate reduced complex viscosity versus the reduced angular frequency obtained from TTS at $-20^{\circ} \mathrm{C}$ as reference temperature, $1 \%$ shear strain

Regarding the master curves in Figure SI-8, it appears clearly that for most of the polyricinoleate tested, no viscosity plateau is observed at low frequencies, with the noticeable exceptions of PRic- 6 and PRic-8. In these two cases, viscosity plateau is observed for $\omega<1$ rad. $\mathrm{s}^{-1}$ in the case of PRic- 6 and $\omega<0.1$ rad. $\mathrm{s}^{-1}$ in the case of PRic- 8 allowing determination of a Newtonian viscosity at $-20^{\circ} \mathrm{C}$

$$
\begin{aligned}
& \text { PRic-6: } \eta^{*}-20{ }^{\circ} \mathrm{C}=3010 \pm 230 \text { Pa s } \\
& \text { PRic-8: } \eta^{*}-20{ }^{\circ} \mathrm{C}=34900 \pm 1500 \mathrm{~Pa} \mathrm{~S}
\end{aligned}
$$

Then the viscosity could be calculated at $20^{\circ} \mathrm{C}$ using Andrade law.

For the other PRic samples, the viscosity was not stable with the frequency in the range of frequencies and temperatures tested. Newtonian viscosities were then determined using creep experiments in which several shear stress were applied on the polymer sample and the resulting shear strain was measured as a function of time. Different temperatures were used for each creep experiments, a viscosity and steady state shear rate value were reported. Viscosity obtained was plotted versus the shear rate as displayed in Figure SI-10. The obtained viscosities were almost independent of the the shear rate and thus considered as Newtonian, Although a beginning of shear thinning is detected in Pric-10

PRic-7: $\eta_{20}{ }^{\circ} \mathrm{C}=28.80 \pm 0.03 \mathrm{~Pa} . \mathrm{s}$ 
PRic-9: $\eta_{200}{ }^{\circ} \mathrm{C}=124.8 \pm 2.2$ Pa.s

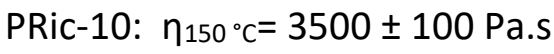

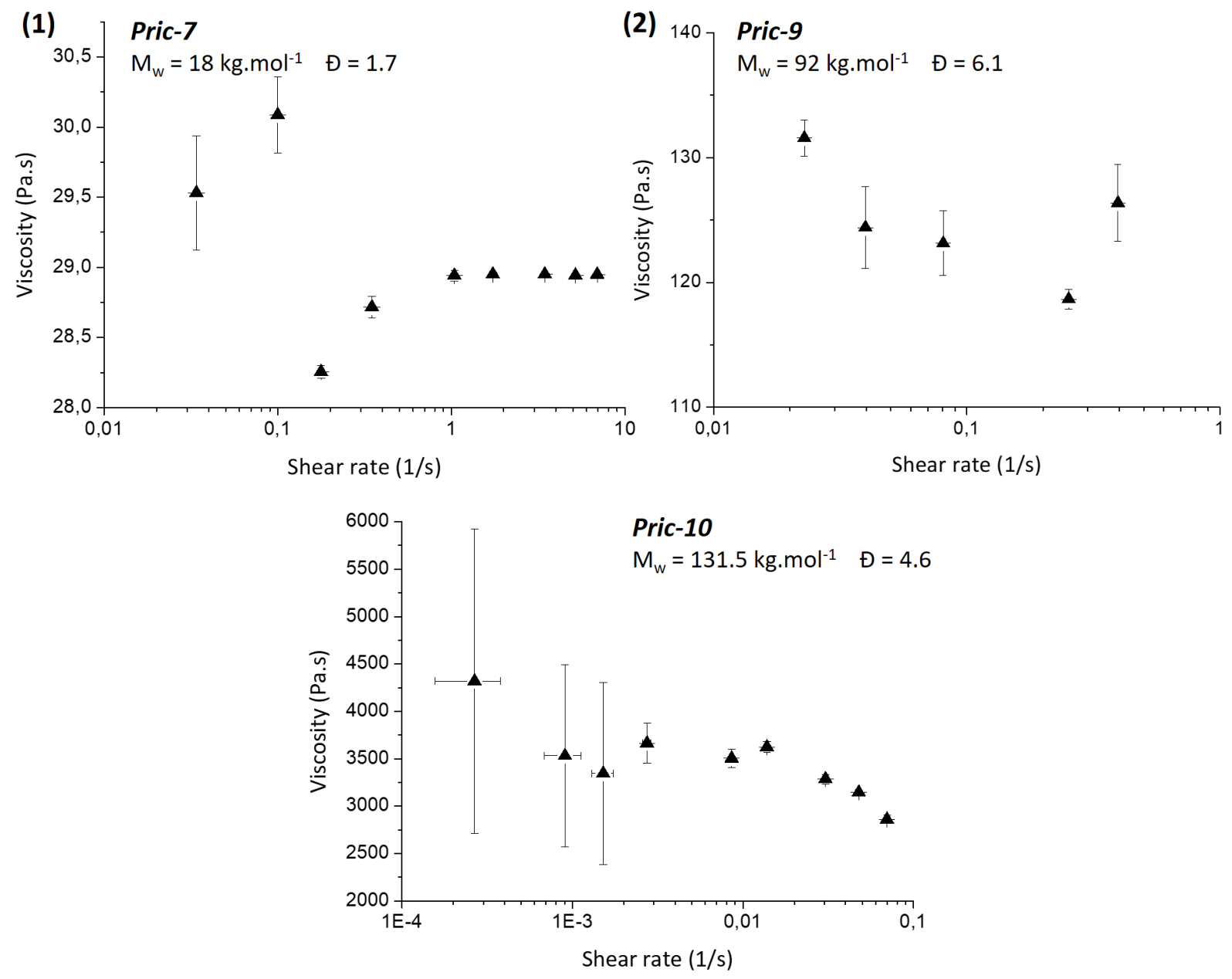

Figure SI - 10: Viscosity versus shear rate obtained by creep measurements. (1) PRic-7 performed at $20^{\circ} \mathrm{C}$, (2) PRic-9 performed at $200^{\circ} \mathrm{C}$ and (3) PRic-10 performed at $150{ }^{\circ} \mathrm{C}$

For Pric 8 and Pric 6, the Newtonian viscosity at $20^{\circ} \mathrm{C}$ were calculated from the value of Newtonian viscosity obtained with master curves of complex viscosity versus frequency at a temperature reference of $-20^{\circ} \mathrm{C}$. for Pric -7 , Pric 9 and Pric 10 Newtonian viscosities were obtained by creep experiments, as they could not be determined through dynamic experiments.. As the temperature chosen for creep experiments of Pric 9 and Pric $10\left(200^{\circ} \mathrm{C}\right.$ and $150^{\circ} \mathrm{C}$ respectively ) were far above the reference temperature of $-20^{\circ} \mathrm{C}$, another master curve $\left(\mathrm{G}^{\prime}, \mathrm{G}^{\prime}\right.$, $\mathrm{f}(\mathrm{aTw})$ have been realized for Pric-9 and Pric-10 at a reference temperature of $80^{\circ} \mathrm{C}$ and new shift factor aT has been calculated. Again these shift factor obey an Andrade law but slight variation of activation energy compared to the reference temperature of $-20^{\circ} \mathrm{C}$ was obtained 
(Table SI-2). We used this activation energy for PRic 9 and Pric 10 to calculate the Newtonian viscosity at $20^{\circ} \mathrm{C}$.
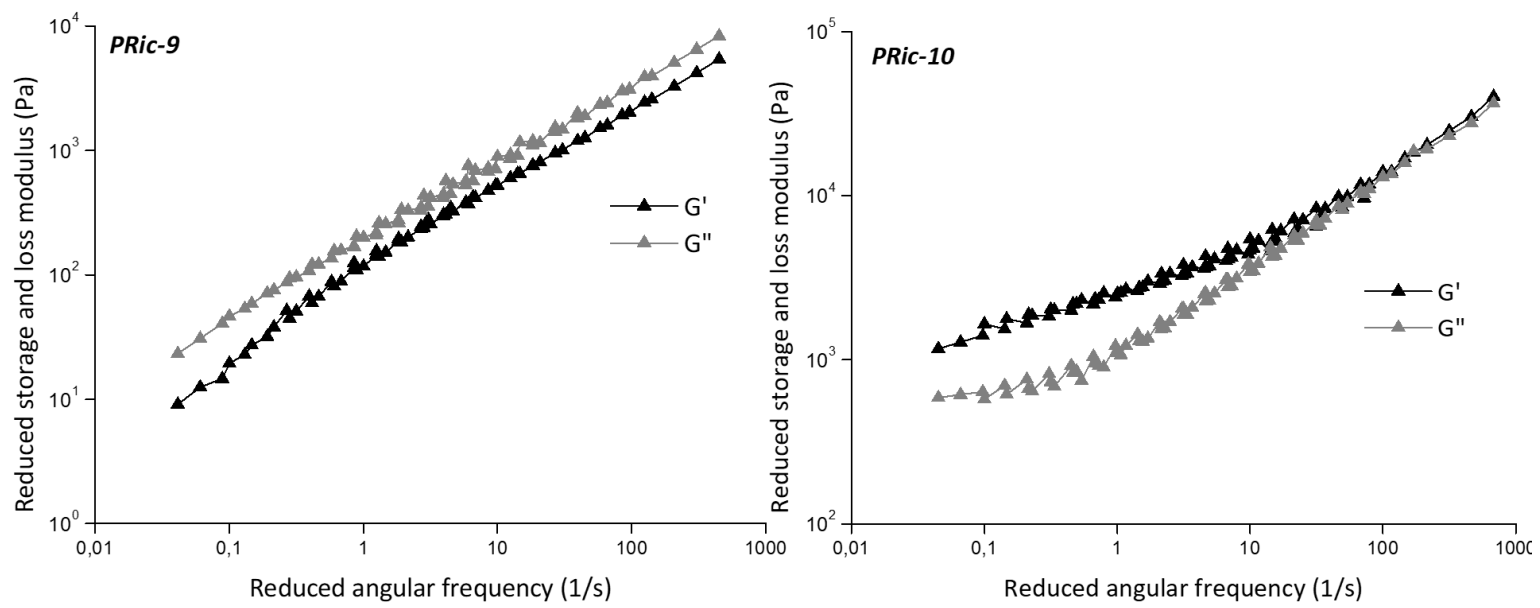

Figure SI-11: Master curves at $80^{\circ} \mathrm{C}$ of PRic- 9 and PRic- 10 samples. Reduced storage and loss modulus are expressed versus the reduced angular frequency

Table SI-3: Translation factor and activation energy obtained by TTS master curves at $-20^{\circ} \mathrm{C}$.

\begin{tabular}{|c|c|c|c|c|c|c|c|}
\hline & $\mathrm{T}\left({ }^{\circ} \mathrm{C}\right)$ & -30 & $-20 *$ & -10 & 0 & 20 & $\mathrm{Ea}\left(\mathrm{kJ} . \mathrm{mol}^{-1}\right)$ \\
\hline & $a_{T}$ & 5.911 & 1 & 0.173 & - & - & \\
\hline \multirow[t]{2}{*}{ PRic-6 } & $a_{\text {Tcalc }}$ & 6.256 & 1 & 0.184 & 0.038 & 0.002 & 93.72 \\
\hline & \%error & 5.62 & 0 & 5.67 & - & - & \\
\hline & $a_{T}$ & 2.592 & 1 & 0.350 & 0.143 & 0.042 & \\
\hline \multirow[t]{3}{*}{ PRic-7 } & $a_{\text {T calc }}$ & 2.634 & 1 & 0.408 & 0.178 & 0.040 & 49.57 \\
\hline & \%error & 1.74 & 0 & 16.97 & 24.65 & 5.21 & \\
\hline & $a_{T}$ & 2.832 & 1 & 0.328 & 0.125 & 0.025 & \\
\hline \multirow[t]{3}{*}{ PRic-8 } & $\boldsymbol{a}_{T_{\text {calc }}}$ & 3.028 & 1 & 0.359 & 0.139 & 0.025 & 56.63 \\
\hline & \%error & 6.93 & 0 & 9.41 & 11.25 & 2.58 & \\
\hline & $a_{T}$ & 2.937 & 1 & 0.332 & 0.128 & 0.030 & \\
\hline \multirow[t]{3}{*}{ PRic-9 } & $\boldsymbol{a}_{T \text { calc }}$ & 2.921 & 1 & 0.371 & 0.148 & 0.029 & 54.80 \\
\hline & \%error & 0.531 & 0 & -11.767 & -16.115 & 4.959 & \\
\hline & $a_{T}$ & 2.612 & 1 & 0.356 & 0.141 & 0.030 & \\
\hline \multirow[t]{2}{*}{ PRic-10 } & $a_{T \text { calc }}$ & 2.846 & 1 & 0.380 & 0.155 & 0.031 & 53.47 \\
\hline & \%error & 8.957 & 0 & -6.996 & -10.430 & -4.458 & \\
\hline
\end{tabular}

$*$ : Reference temperature $-a_{T \text { calc }}$ are shift factors from computation using Arrhenius law 
Table SI-4: Translation factor and activation energy obtained by TTS master curves at $80^{\circ} \mathrm{C}$ as reference.

\begin{tabular}{|c|c|c|c|c|c|c|c|c|c|}
\hline & $\mathrm{T}\left({ }^{\circ} \mathrm{C}\right)$ & 20 & 40 & 60 & $80 *$ & 100 & 150 & 200 & Ea (kJ.mol $\left.{ }^{-1}\right)$ \\
\hline \multirow{3}{*}{ PRic-9 } & $a_{T}$ & 30.457 & 8.497 & 2.6867 & 1 & 0.4128 & - & - & \\
\hline & $a_{T \text { calc }}$ & 30.365 & 8.415 & 2.721 & 1 & 0.4091 & - & 0.0146 & 43.9 \\
\hline & \%error & 0.3013 & 0.953 & 1.2865 & 0 & 0.8885 & - & - & \\
\hline \multirow{3}{*}{ PRic-10 } & $a_{T}$ & 21.48 & 5.387 & 2.294 & 1 & 0.4504 & - & - & \\
\hline & $a_{T \text { calc }}$ & 20.061 & 6.498 & 2.410 & 1 & 0.456 & 0.089 & - & 42.98 \\
\hline & \%error & 6.608 & 20.62 & 5.045 & 0 & 1.243 & - & - & \\
\hline
\end{tabular}

*: Reference temperature $-a_{T \text { calc }}$ are shift factors from computation using Arrhenius law

\section{REFERENCE}

1 D. Van Krevelen and K. Nijenhuis, Properties of Polymers, Elsevier, 1992, vol. 16. 